\title{
Do Fiscal TRANSFERs AlLEVIATE Business TAX COMPETITION? EVIDENCE FROM GERMANY
}

\author{
PETER EGGER \\ MARKO KOETHENBUERGER \\ MICHAEL SMART
}

CESIFO WORKING PAPER NO. 1955

CATEGORY 1: PubliC FinANCE

MARCH 2007
An electronic version of the paper may be downloaded
- from the SSRN website:
www.SSRN.com
- from the RePEc website:
Www.RePEc.org
- from the CESifo website:
www.CESifo-group.de




\title{
Do Fiscal Transfers AlleViate Business TAX COMPETITION? EVIDENCE FROM GERMANY
}

\begin{abstract}
The paper empirically analyzes the incentive effects of equalizing transfers on business tax policy by exploiting a natural experiment in the state of Lower Saxony which changed its equalization formula as of 1999. We resort to within-state and across-state difference-indifference estimates to identify the reform effect on municipalities' business tax rates. Confirming the theoretical prediction, the reform had a significant impact on the municipalities' tax policy in the four years after the reform with a "phasing out" of the effect starting in the fourth to fifth year. The finding is robust to various alternative specifications.

JEL Code: H71, H25.
\end{abstract}

Keywords: equalization grants, tax competition, local public finance, fiscal capacity equalization.

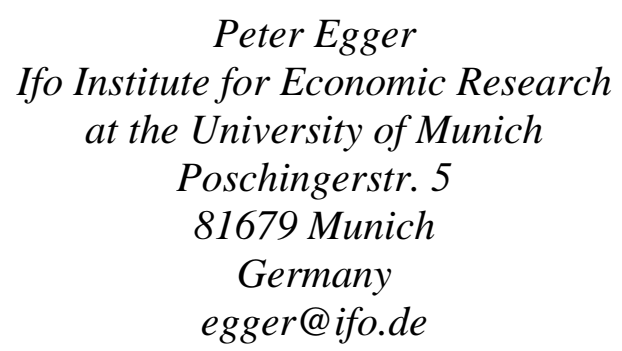

\author{
Marko Koethenbuerger \\ Center for Economic Studies and CESifo \\ at the University of Munich \\ Schackstr. 4 \\ 80539 Munich \\ Germany \\ marko.koethenbuerger@ces.vwl.uni- \\ muenchen.de
}

\author{
Michael Smart \\ Department of Economics \\ University of Toronto \\ 150 St. George St. \\ Toronto ON M5S $3 G 7$ \\ Canada \\ msmart@economics.utoronto.ca
}

We are grateful for comments by seminar participants in Bergen (NHH, March 2006), Berlin (WZB, May 2006), Helsinki (HECER, October 2006), Paphos (IIPF meeting, August 2006), and Paderborn (July 2006). The usual disclaimer applies. 


\section{Introduction}

It is a familiar shibboleth among public finance economists that decentralization of business taxation to lower-level governments can give rise to undesirable competition for mobile tax bases, and a "race to the bottom" in tax rates. Despite such concerns, a number of authors have recently observed that a system of intergovernmental transfers similar to those existing in many countries may in principle serve as a corrective device for local business tax competition, discouraging beggar-thy-neighbor tax policies and even under some conditions guaranteeing the efficiency of decentralized policies.

Under such transfer systems, known as capacity equalization or foundation grants, each government receives a transfer equal to the difference between its measured tax base and either the average base of all regions or a measure of fiscal needs, multiplied by some target tax rate. Thus a capacity equalization grant is an equity-enhancing device that insures that each jurisdiction can achieve some target level of spending determined by federal authorities, as long as it sets its own tax rate at least as high as the target level. ${ }^{1}$ As Smart (1998) and Köthenbürger (2002) observed, however, an increase in local tax rates causes measured tax bases to decline, as taxpayers shift to other regions of the country or to other, more lightly taxed activities - and so causes capacity equalization transfers to rise. Thus the grants in effect subsidize tax increases and penalize tax cuts by local governments, and the effect is larger the greater is the equalization rate (sometimes referred to as "taxback rate") at which deficiencies in local fiscal capacity are compensated through the transfer formula. ${ }^{2}$

In this paper, we look for empirical evidence of the effects of equalization grants on local tax policy using data on a large set of German municipalities. The German case is an especially interesting one to examine, since municipalities there levy a tax on resident businesses, known as Gewerbesteuer, at rates that average about 16 per cent of incomes. Since interjurisdictional mobility and the pressures of tax competition in such a setting should in principle be high, the equalization grants system may play an important, if

\footnotetext{
${ }^{1}$ The capacity equalization principle currently forms the basis for transfer systems in Australia, Canada, Germany, and Switzerland, as well as local school district finance formulas in many US states.

${ }^{2}$ This effect is clearest when considering a receiving region with a tax rate equal to the target tax rate at which capacity deficiencies are compensated: At this point, further increases in the rate will appear to create no deadweight loss to the region, as the increase in equalization transfers exactly compensates for marginal losses in private consumption. Thus equalization tends to drive tax rates above the target tax rate.
} 
unintended, role in maintaining current rates of taxation.

Our empirical approach relies on differences in tax-setting incentives facing municipalities that qualify for the systems of "regular" and "supplementary" equalization transfers, and in particular the court-ordered reforms in eligibility for supplementary transfers that occurred in the state of Lower Saxony (Niedersachsen) in 1999. Regular equalization transfers are available to municipalities whose fiscal capacity falls below a target level, while supplementary transfers are targeted at municipalities with considerably lower than average fiscal capacity. About three-quarters of the 1022 municipalities in Lower Saxony receive one or both types of equalization transfers. The effect of the 1999 reform was to reduce the equalization rate facing municipalities eligible for supplementary transfers, while increasing the equalization rate for other, ineligible municipalities. The former group of municipalities is therefore hypothesized to levy lower tax rates than the latter one in response to the reform.

Since the equalization formula itself implicitly defines the sets of municipalities that are eligible and ineligible for supplementary grants, identification of incentive effects of equalization must address the inherent problems of self-selection. The reason is that a jurisdiction can to some extent influence the fiscal capacity and thus the program type it is eligible for. The corresponding equalization transfer eligibility and tax policy are then both endogenous. This may generate a bias with simple mean comparison estimates of a transfer reform on the tax setting of the eligible municipalities relative to the non-eligible ones. To avoid this bias, we address the problem of self-selection by applying switching regression and matching procedures in the empirical analysis.

Two sources of heterogeneity enable the identification of the reform effect on tax rates. First, to the extent that municipalities respond heterogeneously to a change in supplementary transfers within a federal union (as the reform entails for municipalities in Lower Saxony), the differential effect can be estimated using differences in business tax policy between the subsample of supplementary transfer recipients and an appropriate within-state control group. The construction of the latter group should pay attention to the problem of self-selection into supplementary transfer eligibility. Second, since municipal equalization schemes differ among German states (Länder), one can identify the effect of a transfer reform by comparing the change in tax policy between municipalities in the reforming and a non-reforming state. In our analysis, we estimate the reform effect on municipalities in Lower Saxony by a comparison with the 2056 municipalities in the state of Bavaria, which experienced no reform in the equalization system over our 
1994-2004 sample period.

Empirical work on the incentive effects of equalization programs has evolved only recently. Baretti et al. (2002) provide evidence that the equalization system among German states implicitly taxes tax revenues allocated to states through revenue-sharing arrangements. States do not have explicit taxing powers. Thus, the effect of fiscal equalization on tax policy cannot be identified therein. Hayashi and Boadway (2001) report empirical results consistent with the idea that Canadian provinces conform in their tax rate setting to the tax rate of the province of Ontario which predominantly determines the average provincial tax rate used to compute the standard fiscal capacity in the Canadian equalization formula. Smart (2006) extends their approach and finds a robust effect of equalization on the tax policies of grantreceiving governments in Canada. Dahlby and Warren (2003) find a similar incentive effect for Australia. Buettner (2006) examines the combined effect of vertical (revenue-sharing) and horizontal (equalization) grants on the tax policies of municipalities in the German state of Baden-Württemberg, and finds significant responses. The identification of this effect however relies on year-to-year changes and within-state/year cross-sectional variation in the equalization rate, which may be subject to the self-selection problems just discussed. ${ }^{3}$

The problem of self-selection has not yet surfaced at the heart of existing research on the incentive effects of equalization programs. Furthermore, previous work has not exploited information on a large-scale reform of the equalization system in one state of a federal union to identify the effect on tax rates. Only the latter enables an identification of the reform-induced effects on different groups of municipalities according to their transfer eligibility status. The reason is that, with the eligibility status being endogenous, intra-state variation in the outcome variable is required to identify the differential impact on treatment and control in the reform state, Lower Saxony, while inter-state variation is required to identify the average effect in the

\footnotetext{
${ }^{3}$ In the German system of fiscal arrangements, municipalities are required to levy a tax on their business tax bases that is transferred to higher-level (county and state) governments, as well as receiving payments from or contributing to the equalization grant system. Formally, vertical revenue sharing has an effect that is analogous to horizontal equalization, to the extent that county-level taxes are "passed on" to firms by municipalities. Buettner (2006) estimates the combined effect of the two. In contrast, our paper looks at the effect of horizontal equalization alone. As well, Buettner's approach to identifying the tax-raising effect relies on variation in county-level tax rates, which may be correlated with other determinants of tax rates of municipalities within the county. In contrast, our estimates are identified solely from the asymmetric changes in equalization rates induced by a state-wide policy reform.
} 
reform state (across state difference in difference analysis).

We find a significant effect of the reform on local business tax rates. As hypothesized, tax rates in eligible municipalities fell gradually in the four years following the reform, relative to ineligible municipalities' rates. The overall impact on the gap in business tax rates amounted to about 0.95 percentage points, about five percent of their original level. This estimated average treatment effect however masks important heterogeneity in response to the reform. According to our estimates, the magnitude of the estimated exogenous treatment effect is downward biased by about 83 percent. On the basis of the between-state difference in difference analysis, moreover, we conclude that the reform raised the average level of taxes in the reform state. These results are robust to alternative choices of the estimation procedures and the inclusion of alternative control variables.

The remainder of the paper is organized as follows. Section 2 develops the theoretical hypotheses. Section 3 reviews the features of the German municipal equalization system and explains the reform effects from a theoretical perspective. The data are presented in Section 4, while Sections 5 and 6 summarize the empirical strategy and the results. The last section concludes with a summary of the major findings.

\section{Equalization and tax competition}

To understand the incentive effects of equalization grants, consider a version of the model in Köthenbürger (2002) and Bucovetsky and Smart (2006). A federation consists of two jurisdictions, labelled $i$ and $j$, each with a single resident and a single tax base. Jurisdiction $i$ levies tax rate $\tau_{i}$ on its own base $B_{i}$. Let the tax base in jurisdiction $i$ be a linear function of tax rates in the federation,

$$
B_{i}=B_{i}^{0}+c \tau_{j}-a \tau_{i}
$$

where $B_{i}^{0}$ and $a>c \geq 0$ are parameters. Thus the model incorporates a fiscal spillover (e.g. tax competition where $B_{i}$ is the capital tax base) among jurisdictions when $c>0$, since a rise in the tax rate in one jurisdiction causes a rise in the other jurisdiction's tax base.

Each jurisdiction receives from the central government an equalization grant that compensates for differences in the size of the local tax bases. For jurisdiction $i$, the transfer formula is

$$
T_{i}=\alpha_{i}\left(N_{i}-B_{i}\right),
$$


where $N_{i}$ is a parametric lump-sum component to the grant representing the jurisdiction's deemed "fiscal need", and $\alpha_{i}$ is the rate at which the grant is reduced for each unit of local fiscal capacity or tax base $B_{i}$. (The variables for jurisdiction $j$ are defined analogously.) Note that we allow marginal equalization rates $\alpha_{i}$ to differ between jurisdictions; capturing the possibility that jurisdictions operate on different segments of a non-linear equalization scheme. In particular, this subsumes the case in which one jurisdiction is not eligible for equalization transfers $\left(\alpha_{i}=0\right)$, perhaps because it has exogenous fiscal capacity that exceeds deemed fiscal need, while the other jurisdiction remains eligible for equalization payments $\left(\alpha_{j}>0\right)$.

Consider the problem of a government in region $i$ that seeks to maximize revenue net of federal equalization transfers, and which takes the parameters of the equalization formula and the tax rate of the other jurisdiction as given. ${ }^{4}$ In this model, the optimal tax rate $\tau_{i}$ solves

$$
\max \tau_{i} B_{i}+\alpha_{i}\left(N_{i}-B_{i}\right)
$$

for which the first-order (necessary and sufficient) condition is

$$
B_{i}-a\left(\tau_{i}^{*}-\alpha_{i}\right)=0 .
$$

The first-order condition defines the optimal tax rate in region $i$ as a function of the neighbor region's tax rate and its marginal equalization rate, $\tau_{i}^{*}\left(\tau_{j}, \alpha_{i}\right)$. Using (1) comparative statics on $\tau_{i}$ yields an inverse relationship between $\tau_{i}$ and region $i$ 's marginal equalization rate $\alpha_{i}$.

In the empirical analysis below, we examine the impact of the equalization formula on the reduced form tax rates of affected governments, without regard for the structural interactions among tax rates as embodied in the reaction function $\tau_{i}^{*}\left(\tau_{j}, \alpha_{i}\right)$. To motivate this approach, therefore, we may solve for the Nash equilibrium tax rates of the jurisdictions that constitute a fixed point of the reaction functions. This can be interpreted as a reduced form relationship between tax rates and equalization parameters, $\bar{\tau}_{i}^{*}\left(\alpha_{i}, \alpha_{j}\right) .{ }^{5}$ Our empirical work employs a "difference-in-difference" strat-

\footnotetext{
${ }^{4}$ The Leviathan assumption together with the linearity of the tax base in (1) greatly simplifies the analysis, while preserving the essential features of the incentive effects of equalizing transfers. The linear model was studied by Bucovetsky (1991) inter alia. The effect of equalization transfers on welfare maximizing governments facing non-linear tax bases is addressed in Smart (1998), and the qualitative results are the same.

${ }^{5}$ Following the first-order condition, the reduced form relationship is

$$
\bar{\tau}_{i}^{*}=\frac{2 a}{4 a^{2}-c^{2}}\left(B_{i}^{0}+a \alpha_{i}\right)+\frac{c}{4 a^{2}-c^{2}}\left(B_{j}^{0}+a \alpha_{j}\right) .
$$

Observe that $a>c \geq 0$ is sufficient to guarantee existence of a unique Nash equilibrium. 
egy that examines how the tax rates of jurisdictions change relative to each other in response to a change in their relative marginal rates of equalization. To see this relationship in the theoretical model, we may therefore compute the difference in equilibrium tax rates

$$
\bar{\tau}_{i}^{*}-\bar{\tau}_{j}^{*}=\frac{B_{i}^{0}-B_{j}^{0}}{2 a+c}+\frac{a}{2 a+c}\left(\alpha_{i}-\alpha_{j}\right) \equiv \beta_{i j}+\gamma\left(\alpha_{i}-\alpha_{j}\right) .
$$

The tax differential is positively related to the differential in equalization rates pertaining to the respective jurisdictions.

\section{Equalization transfers in Germany}

In describing the municipal equalization scheme, we focus on the system in Lower Saxony where a reform has been implemented as of 1999 .

The core of the municipal transfer system is: (i) a system of "regular" equalization grants, which compensate for a fraction of the amount by which each municipality's measured taxation capacity falls short of its targeted spending level or "fiscal need", and (ii) a system of supplementary equalization grants, which establish a floor level of spending in each municipality, and equalize 100 per cent of deficiencies up to the floor.

In algebraic terms, let $B_{i}$ denote the measured tax capacity in municipality $i$; that is, the revenues that would be available for local spending purposes if the jurisdiction were to levy a centrally determined reference tax rate on its measured tax bases. ${ }^{6}$ Let $N_{i}$ denote the "fiscal need" or target spending level of the municipality-again, a centrally determined parameter that depends only on the current population of the municipality. Let $\alpha$ be the rate at which capacity deficiencies are compensated under the regular equalization transfer. Finally, let $\beta N_{i}$ denote the spending floor below which deficiencies are fully compensated under the supplementary equalization transfer, where $\beta$ is a centrally (state-level) determined parameter that is common to all municipalities within the same state. The aggregate equalization transfer to the municipality may then be written:

$$
T_{i}\left(B_{i}\right)=\alpha \max \left\{N_{i}-B_{i}, 0\right\}+\max \left\{\beta N_{i}-B_{i}-\alpha\left(N_{i}-B_{i}\right), 0\right\}
$$

\footnotetext{
${ }^{6}$ In practice the fiscal capacity is the jurisdiction's tax base multiplied by a "standard" tax rate. In the sequel we assume a "standard" tax rate equal to unity. Since its level has no formulaic relation to the municipalities' business tax rate choices, the simplification does not impair the analysis of incentive effects.
} 


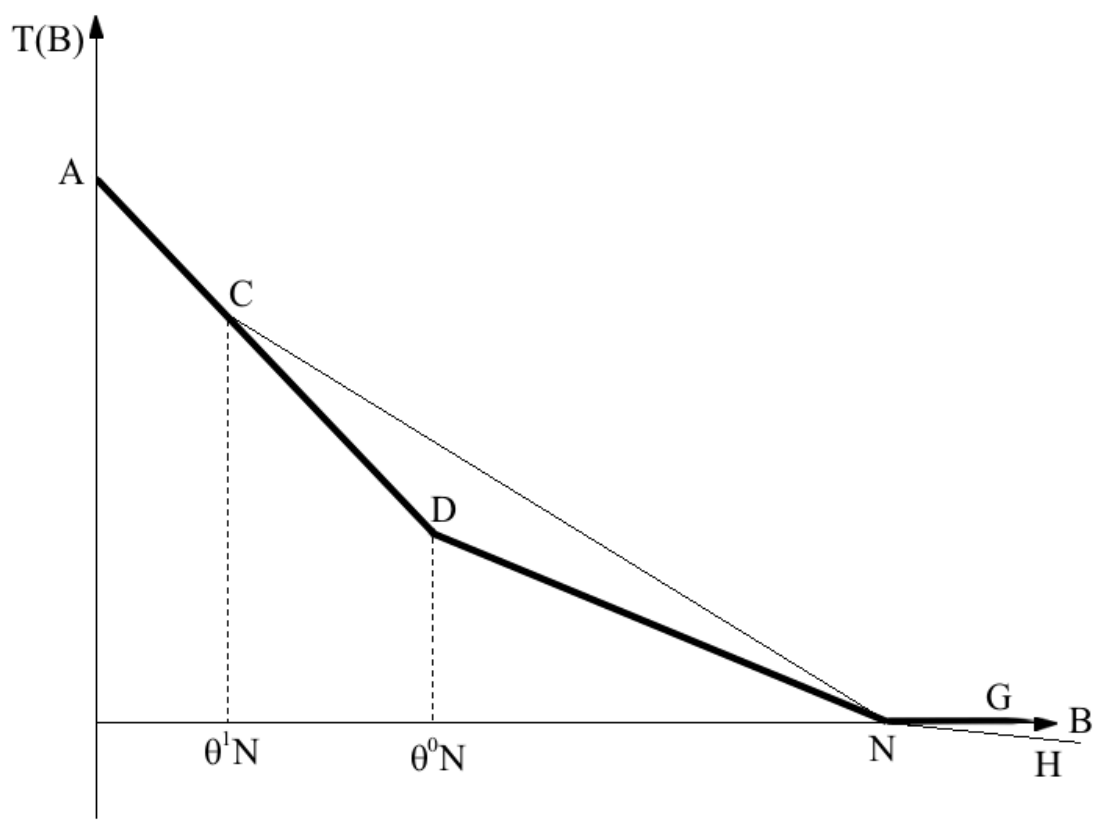

Figure 1: Equalization transfers and incentives.

where the first term corresponds to the regular equalization transfer and the second to the supplementary transfer (which itself depends on the fiscal capacity resulting from the regular transfer). ${ }^{7}$

Observe that the second term in the transfer formula, the supplementary equalization component, is positive if and only if $(\beta-\alpha) N_{i}-(1-\alpha) B_{i}>0$ or

$$
B_{i}<\frac{\beta-\alpha}{1-\alpha} N_{i} \equiv \theta N_{i}
$$

where $\theta<1$. Thus $\theta$ in $(7)$ expresses the fraction of target spending below which capacity deficiencies are fully equalized.

This describes the state's horizontal equalization system in general terms

\footnotetext{
${ }^{7}$ In the transfer system described by equation (6), equalization is on a "gross" basis: each transfer is positive if the corresponding deficiency is positive, and zero otherwise; municipalities with capacity in exceed of fiscal need are not taxed under the formula. In fact, in the 1999 Lower Saxony reform discussed below, municipalities with excess capacity were required to pay 20 per cent of the difference to the state government, converting the actual formula to a partial "net" equalization basis. We return to this issue below.
} 
throughout our sample period. We turn now to the numerical values assumed by the parameters in the formula and the changes in the parameters following the 1999 reform - which is the key to our identification strategy. The reform was initiated by a ruling of the state supreme court in November 1997 which declared the initial system unconstitutional and requested the implementation of a new system as of 1999. The reform prescribed changes in the different equalization rates. Prior to the reform, the regular equalization transfer compensated 50 per cent of deficiencies in capacity below the target level, and the spending floor was established at 80 per cent of the target level; thus $\alpha^{0}=1 / 2$ and $\beta^{0}=4 / 5$ in the pre-reform period, and $\theta^{0}=(4 / 5-1 / 2) /(1 / 2)=3 / 5$ was the threshold fraction of the target below which supplementary equalization was paid. In the 1999 reform, the regular equalization was increased to 75 per cent, while other parameters of the formula remained unchanged; thus $\alpha^{1}=3 / 4, \beta^{1}=4 / 5$, and $\theta^{1}=(4 / 5-3 / 4) /(1 / 4)=1 / 5$. As we will see, this resulted in substantial changes in municipal government incentives.

To understand the incentives for local tax policy induced by the transfer system, it is useful to consider the graph of the equalization formula. Figure 1 expresses the relationship between a municipality's own fiscal capacity $B_{i}$ and its equalization transfers $T_{i}\left(B_{i}\right)$ in both the pre-reform and post-reform periods. The kinked line segment ADNG is the constraint which obtains in the pre-reform period: capacity deficiencies are fully compensated by transfers when $B_{i} \leq \theta^{0} N_{i}$, so the constraint has slope -1 in this interval; 50 per cent of capacity deficiencies are compensated when $\theta^{0} N_{i}<B_{i} \leq N_{i}$, so the slope of the constraint is -0.5 in this interval; and no equalization transfers are paid when $B_{i}>N_{i}$, the slope of the constraint is thus zero to the right of $N_{i}$. The post-reform budget constraint is represented by the kinked line segment ACNH. The effect of the reform was to increase the fraction of capacity deficiencies compensated by regular equalization transfers to 75 per cent and so to increase the slope of the constraint by 0.25 (in absolute value) in the intermediate interval, while reducing the threshold at which supplementary equalization was paid commensurately to $\theta^{1} N_{i}{ }^{8}$ For governments with tax capacity in excess of need, operating on segment NG, no equalization payments were received before or after the reform. In

\footnotetext{
${ }^{8}$ For governments initially operating on segment $\mathrm{AC}$ of the pre-reform constraint, there was no change in marginal incentives. Observe however that the new threshold level was extremely low, at 20 per cent of the target spending level. In consequence, only one municipality has qualified for supplementary transfers in the post-reform period. We categorize this municipality as part of the treatment group 1 despite the fact that there was no change in marginal incentives; this can only lead to attenuation bias in our results.
} 
the post-reform period, however, such municipalities were required to pay 20 per cent of excess tax capacity to the state government, operating now on the segment $\mathrm{NH}$ with slope -0.2 . Such a payment operates exactly like a negative equalization grant with an equalization fraction of one-fifth.

Thus the reform resulted in a rather stark change in the extent to which marginal changes in local resources $B_{i}$ are compensated through the formula. Municipalities may be classified into three groups based on their equalization status prior to the reform. Group 1, corresponding to segment CD of the pre-reform budget constraint, faced a decrease in equalization fraction of 25 percentage points following the reform, while Groups 2 and 3, corresponding to segments DN and NG, faced increases in the equalization fraction of 25 and 20 percentage points, respectively. According to our theory then, tax rates among the former group of governments are predicted to fall, compared to those of the other two groups.

It is this shock to incentives that is the key to our identification strategy, described in further detail below. An obvious concern with this approach is that factors that determine the initial equalization status of a municipality may be related to the unobservable determinants of subsequent innovations in tax rates, so that assignment to treatment and control groups is not ignorable in our analysis. We describe our strategy for dealing with the endogeneity issue in Section 5.

\section{Data}

We use data on municipalities in the state of Lower Saxony over the time period 1994 - 2004. The described reform in Lower Saxony was effective as of 1999. We use data on the business tax rate which is set at the municipal level in Germany, information on the transfer formula as given in (1) before and after the reform for each municipality in Lower Saxony, and socioeconomic characteristics of the respective municipalities such as population (inhabitants, age structure, and population density), income per capita, and the unemployment rate. Also, we account for geographical characteristics of a municipality (land used for agriculture, forests, water sheds, and size of the road network each of which is measured in hectares). Finally, we employ political characteristics such as the party composition of the local government (social democrats, liberals, conservatives, and the greens). All data except unemployment rates are available from the respective statistical office (Statistische Landesamt), most of it is available in a on-line data 
base. ${ }^{9}$ Data on the number of unemployed at the municipal level are taken from the Federal Labor Office (Bundesagentur für Arbeit) - also available on-line. ${ }^{10}$

In some of our estimations, we will employ data on Bavarian municipalities as a control group. In Bavaria, the reform described in Section 3 did not take place. The corresponding socio-economic, geographical and political data come from the Bavarian statistical office. ${ }^{11}$ Again, the unemployment rates are taken from the Federal Labor Office (Bundesagentur für Arbeit).

In the subsequent analysis, we consider all municipalities in Lower Saxony as supplementary transfer eligible ones if they have actually received such transfers in at least one year in the pre-reform period (1994-98). In all estimations, the remaining Lower Saxony municipalities belong to the control group. Table 1 provides details on the number of eligible and non-eligible municipalities, the average business tax rate, the average fiscal capacity per capita as defined by the equalization formula, and the average income per capita across years and municipalities in the respective group. ${ }^{12}$

About three quarters of the 1022 municipalities in Lower Saxony were supplementary transfer eligible in at least one year between 1994 and 1998. The income per capita level is slightly lower in eligible municipalities than in non-eligible ones. On average, they applied a slightly lower business tax rate than their non-eligible counterparts, and their fiscal capacity is significantly lower. To give a first impression of the possible response of tax rates to the reform, we illustrate the development of the business tax rates in Lower Saxony in Figure 2. The vertical bar in the figure indicates the end of the last pre-reform year 1998. Business tax rates in this and earlier years were about 0.15 percentage points higher in non-eligible municipalities than in eligible ones. This is also consistent with the information given in Table 1. Before the reform, there was not much change in this relationship. But the figure suggests that the gap in the two tax rates increased immediately after the reform year. The adjustment in the gap is somewhat sluggish and a new 'steady-state' in the gap seems to be reached only after four years.

The information in Figure 2 may also be inferred from a descriptive comparison along the lines of regression analysis. In Table 2 we consider the

\footnotetext{
${ }^{9}$ The link is http://www1.nls.niedersachsen.de/Statistik/.

${ }^{10}$ The link is http://www.pub.arbeitsamt.de.

${ }^{11}$ The link is https://www.statistikdaten.bayern.de.

${ }^{12}$ The income per capita seems low, but note that the denominator includes all inhabitants of a municipality, irrespective of whether they are working, unemployed, or not in the labor force at all.
} 


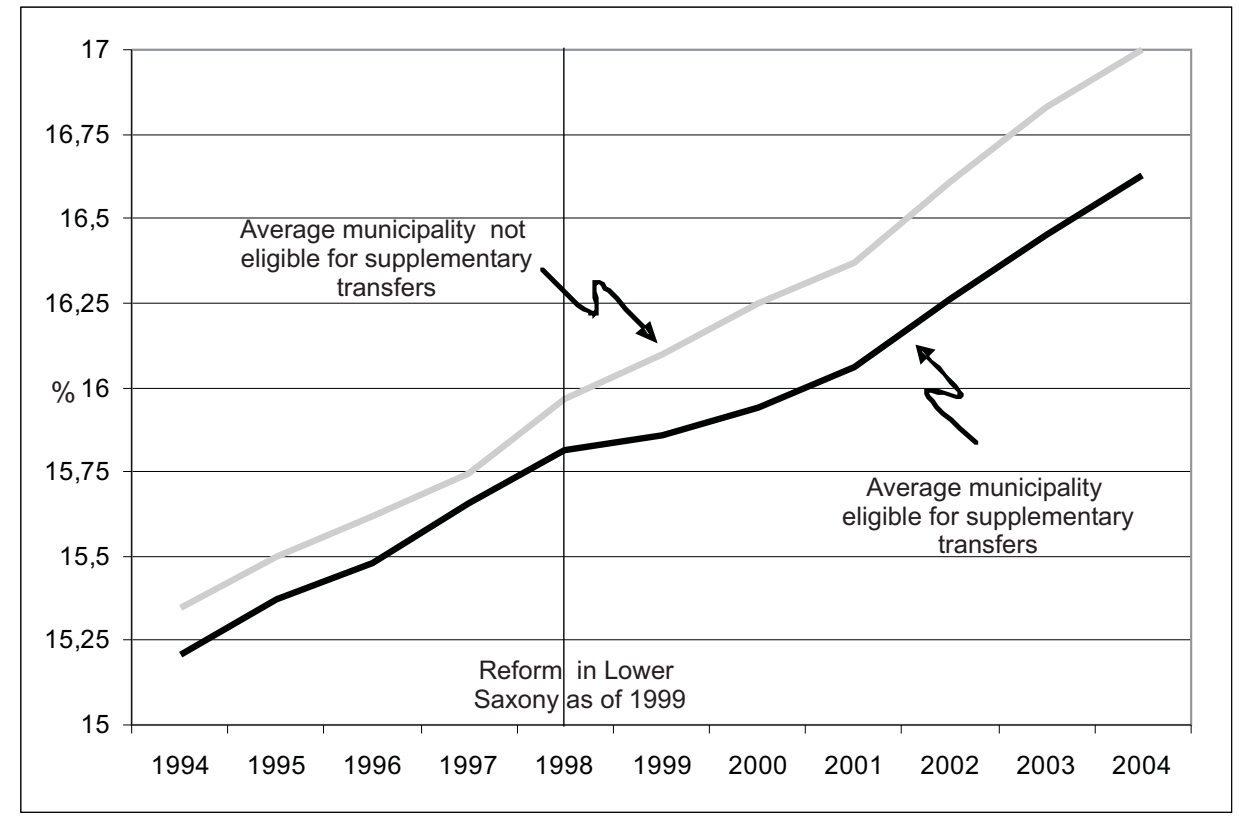

Figure 2: Average business tax rates of eligible and non-eligible municipalities in Lower Saxony.

average business tax rate in the period 1994-97 in eligible versus non-eligible municipalities and compare it to any later year, capturing supplementary transfer eligibility by a dummy variable that is set at one for eligible municipalities and at zero for non-eligible ones. Of course, since 1998 was actually not covered by the reform the change in the eligible regions should be as large as in the non-eligible ones so that the gap does not increase. Hence, the coefficient of the eligibility status dummy variable should be close to zero for 1998. In the subsequent periods, the increase in the gap should show up in an increasingly negative coefficient of the dummy variable of interest.

We find, consistent with Figure 2, that the gap opens up in 1999 (hence, here is no indication of anticipation effects in 1998), reaching a level of about -0.25 percentage points from 2003 onwards. The regression representation will be useful for a comparison with the results in the subsequent analysis, where we account for a possible self-selection into supplementary transfer eligibility. The latter seems particularly important for municipalities operating next to the kinks of the budget constraint depicted in Figure 1. For these, a small change in tax policy may significantly change the local slope 
of the non-linear budget constraint.

\section{Empirical strategy}

\subsection{The problem of self-selection into supplementary trans- fer eligibility}

It will be useful to start with a few definitions for portraying the problem of identification of the supplementary transfer reform effect on business tax rates at the municipal level and the outline of the empirical strategy. For convenience, we will refer to the case of supplementary transfer recipient status by index 1 (treatment status) and to the non-recipient status by index 0 (no-treatment status). The corresponding business tax rate of municipality $i$ with and without treatment status is $\tau_{i, 1}$ and $\tau_{i, 0}$, respectively. Since we will focus on differences in differences of the reform effect, it will be useful to define the pre-to-post-reform change in business tax rates of the supplementary transfer eligible units as $\Delta \tau_{i, 1}$, and that one of the ineligible ones as $\Delta \tau_{i, 0}$. Therein, $\Delta$ is the difference operator across periods.

Notice that there are two treatments of interest, here: the reform effect, which may be viewed as being exogenous from the viewpoint of a municipality, and the supplementary transfer status, which may be endogenous. Let us refer to the binary supplementary transfer eligibility treatment for municipality $i$ as $Z_{i}$ with $Z_{i}=1$ in the treatment case (as $B_{i}<\theta^{0} N$ in Figure 1) and $Z_{i}=0$ otherwise. Let us first focus on differences in business tax rates between the pre- and post-reform periods for Lower Saxony municipalities only. Then, we see that average effect of the exogenous treatment, namely the supplementary transfer reform, is simply a constant. However, in case of an endogenous selection of municipalities into supplementary transfer eligibility status, the change in business tax rates between the pre- and post-reform periods will depend on this endogenous selection. Providing a consistent identification of both the main reform effect and its interaction effect with the status of transfer eligibility on business tax rates $\left(\Delta \tau_{1}-\Delta \tau_{0}\right)$ is central to the paper.

The econometrics literature emphasizes the role of two core concepts of treatment effects: the average treatment effect (see Rubin, 1983) being defined as $A T E \equiv E\left[\Delta \tau_{1}-\Delta \tau_{0}\right]$, where, in our case, $\Delta \tau_{1}$ and $\Delta \tau_{0}$ are random vectors of changes in business tax rates from the population of municipalities of interest; and the average treatment effect on the treated (see Heckman, 1997), being defined as $A T T \equiv E\left[\Delta \tau_{1}-\Delta \tau_{0} \mid Z=1\right]$. Hence, ATE is the unconditional, expected change in business tax rates associated 
with the reform effect for a randomly drawn municipality. In contrast, ATT measures the expected treatment effect on a municipality that is randomly drawn only from the sub-population of the actually supplementary transfer eligible units.

If the supplementary transfer eligibility status were randomized across municipalities, $Z$ would be independent of $\left(\Delta \tau_{1}, \Delta \tau_{0}\right)$. Then, $E\left[\Delta \tau_{1}-\right.$ $\left.\Delta \tau_{0}\right]=E\left[\Delta \tau_{1}-\Delta \tau_{0} \mid Z=1\right]$ implying that $A T E=A T T$. Furthermore, the simple difference in the means of the pre-to-post-reform change in business tax rates among the eligible and ineligible municipalities ${ }^{13}$ is an unbiased, consistent, and asymptotically normal estimate of ATE and ATT. However, if municipalities internalize their possible influence on the slope of the budget constraint and adjust their tax rates accordingly, this creates a problem of self-selection into treatment. Then, the assumption of a randomized or exogenous treatment is not tenable anymore, rendering the simple difference-in-means estimator of the reform-induced supplementary transfer treatment effect (of both ATE and ATT) on changes in business tax rates biased and inconsistent. Accordingly, the response to the tax reform can not be estimated by an ordinary least squares approach as in Table 2 anymore.

\subsection{Cures for self-selection}

The micro-econometrics literature on program evaluation suggests several alternative avenues of how to recover consistent estimates of ATE and ATT under self-selection. Here, we focus on those approaches that involve the formulation of a non-linear probability model to estimate the endogenous selection into treatment (in our case, the probability that a municipality is eligible for supplementary transfers). We can think of the estimation of ATE or ATT as a two-stage problem, where the binary choice selection model is to be estimated in the first stage. In first stage regression, we determine the probability of $Z=1$ by a set of observable determinants. Let us refer to the latter determinants as $\mathbf{W}$, which is an $N \times k_{1}$ matrix, where $N$ indicates the number of (treated plus untreated) observations in the sample, and $k_{1}$ is the number of regressors included in the non-linear probability model assuming either a normal or a logistic distribution function. In general, there are two possibilities to obtain consistent estimates of ATE or ATT. One involves the use of instrumental variable techniques (Wooldridge, 2002). The other adopts the assumption of ignorability of treatment given the covariates collected in W (Rosenbaum and Rubin, 1983). In the subsequent analysis,

\footnotetext{
${ }^{13} \mathrm{As}$ is easily available from descriptive statistics or as a simple exogenous dummy variable estimate in a regression of $\Delta \tau_{i}$ on $Z_{i}$ (where $\Delta$ is the difference operator).
} 
we will in particular make use of the latter, while an application of the former is relegated to the sensitivity analysis.

In our context, the assumption of ignorability of treatment given the covariates entails that provided the correlation between the binary supplementary transfer eligibility $Z$ and the business tax rate outcome $\left(\Delta \tau_{1}, \Delta \tau_{0}\right)$ can be eliminated by conditioning on $\mathbf{W}$, we obtain consistent estimates of ATE and ATT. ${ }^{14}$ Two prominent approaches to estimate treatment effects based on the assumption of ignorability of treatment conditional on a set of observable variables ${ }^{15}$ are (i) selection control procedures based on the switching regression model and (ii) matching based on the propensity score.

As an (intuitively appealing) alternative to the aforementioned procedures we can restrict the set of municipalities to those for which a selfselection problem is less of a concern, i.e. those which do not operate in the close neighborhood of the kink $D$ of the transfer formula depicted in Figure 1. We present an analysis along these lines in section 6.3.

\section{Results}

\subsection{Switching regression model}

We first apply a switching regression model. Let us decompose the outcomes for the treated and the untreated municipalities $\left(\Delta \tau_{k}\right.$ with $\left.k=0,1\right)$ into their mean $\left(\mu_{k}\right)$ and a stochastic part $\left(\nu_{k}\right), \Delta \tau_{k}=\mu_{k}+\nu_{k}$. Then, we may use the regression model $\Delta \tau=\mu_{0}+\beta Z+\epsilon$ to estimate ATE, where $\beta=\left(\mu_{1}-\mu_{0}\right)$ reflects ATE and $\epsilon=\nu_{0}+Z\left(\nu_{1}-\nu_{0}\right)$ is an error term which obviously depends on the supplementary transfer eligibility status $Z$. Since the business tax rate outcome $\Delta \tau$ depends on $Z$, this is referred to as a switching regression model. A two-step estimator that yields a consistent estimate of ATE can be obtained as follows. First, estimate the probability of being eligible for supplementary transfers depending on a set of instru-

\footnotetext{
${ }^{14}$ The assumption implies conditional mean-independence, which means that even though $\left(\Delta \tau_{1}, \Delta \tau_{0}\right)$ and $Z$ are correlated (through self-selection), $E\left[\Delta \tau_{0} \mid \mathbf{W}, Z\right]=$ $E\left[\Delta \tau_{0} \mid \mathbf{W}\right]$ and $E\left[\Delta \tau_{1} \mid \mathbf{W}, Z\right]=E\left[\Delta \tau_{1} \mid \mathbf{W}\right]$. Hence, there is a set of observable variables collected in $\mathbf{W}$ that can remove the correlation between $\left(\Delta \tau_{1}, \Delta \tau_{0}\right)$ and $Z$, and after conditioning on $\mathbf{W}$, we can obtain consistent estimates of ATE and ATT. Under conditional mean-independence, ATT conditional on $\mathbf{W}$ is defined as $\operatorname{ATT}(\mathbf{W}) \equiv E\left[\Delta \tau_{1}-\right.$ $\left.\Delta \tau_{0} \mid \mathbf{W}, Z=1\right]$ and ATE conditional on $\mathbf{W}$ is defined as $A T E(\mathbf{W}) \equiv E\left[\Delta \tau_{1}-\Delta \tau_{0} \mid \mathbf{W}\right]$. Notice that ATT and ATE are identical under conditional mean-independence, and no further restrictions on joint or conditional distributions are required for identification.

${ }^{15}$ Due to the reliance on a set of observables, the approach is sometimes also referred to as selection on observables (Heckman and Robb, 1985; Moffitt, 1996).
} 
ments $\mathbf{W}=[\mathbf{X}, \mathbf{Y}]$, where $\mathbf{X}$ is an $N \times k_{2}$ matrix of exogenous regressors in the second stage model and $\mathbf{Y}$ is an $N \times k_{1}$ set of identifying instruments in the first stage model, with $k_{1}$ denoting the number of regressors in the second stage. Second, determine the expected value of business tax rates conditional on supplementary transfer eligibility, a set of exogenous variables in the second stage model (collected in the matrix $\mathbf{X}$ ), and on the set of instruments in the first stage $(\mathbf{W})$ as: ${ }^{16}$

$E(\Delta \tau \mid Z, \mathbf{X}, \mathbf{W})=\alpha+\beta Z+\mathbf{X} \gamma+\rho_{1} Z \phi(\mathbf{W} \delta) / \Phi(\mathbf{W} \delta)+\rho_{2} Z \phi(\mathbf{W} \delta) /[1-\Phi(\mathbf{W} \delta)]$

where $\mathbf{W} \delta=\delta_{0}+\mathbf{X} \delta_{1}+\mathbf{Y} \delta_{2}$. This is a generalized version of the Heckman (1978) framework (Heckman's estimator is based on a single parameter $\rho$ in the second stage model), which provides an unbiased, consistent, and asymptotically normal estimate of $\beta$ (i.e., ATE) under standard assumptions. ${ }^{17}$ Define $\nu_{k}=g_{k}(\mathbf{X})+e_{k}$ with $E\left(e_{k}, \mathbf{W}\right) \forall k=1,0$ referring to treated and untreated municipalities, respectively, to indicate that $\left(a, e_{0}, e_{1}\right)$ is independent of $\mathbf{W}$ with a trivariate normal distribution by assumption. Then, ATE can easily be estimated by a two-stage procedure similar to the one proposed by Heckman (1978): estimate a probit or logit model to obtain estimates of $\phi(\mathbf{W} \delta)$ (i.e., the density of the standard normal evaluated at $\mathbf{W} \delta$ ) and $\Phi(\mathbf{W} \delta)$ (i.e., the cumulative density of the standard normal evaluated at $\mathbf{W} \delta$ ); plug these estimates in the two inverse Mill's ratios of the second stage linear regression model. Then, the coefficients of the two Mill's ratios $\rho_{k}$ will control for the selection bias, rendering the estimates of ATE as captured by $\beta$ unbiased, consistent, and asymptotically normal.

\subsubsection{Propensity to be supplementary transfer eligible for Lower Saxonian municipalities}

We assume that $\mathbf{W}$ consists of the following socio-economic and geographical characteristics: a municipality's area of agricultural land in hectares (as a measure of its degree of industrialization); the area of forest space in hectares; the area of watersheds in hectares (as a measure of remoteness); the area of paved streets in hectares (as a measure of a municipality's infrastructure endowment); per-capita GDP as of 1993 (i.e., in the pre-treatment

\footnotetext{
${ }^{16}$ Note that in the absence of Y ATE can still be identified if the non-linearity of the first-stage model is sufficiently informative (see Cameron and Trivedi, 2005).

${ }^{17}$ The assumptions are that functional forms are as indicated and that supplementary transfer eligibility can be written as an indicator function of the form $Z=1[\mathbf{W} \delta+$ $a \geq 0$ ] and $a$ is independently and identically distributed following a standard normal distribution.
} 
period); population size as of 1993; the change in population density between the pre- and post-treatment periods; the share of the population below an age of 15 years as of 1993; and squared values of these eight variables. Hence, including the constant, the column rank of $\mathbf{W}$ is 17 .

Most notably the geographical variables are hypothesized to influence the fiscal capacity, but to be uncorrelated with the dependent variable of the second-stage regression which is the change in the tax rate following the reform. To illustrate the reasoning, return to the theoretical model of section 2. Consider the baseline component of municipality $i$ 's tax base $B_{i}^{0}$ to summarize the aforementioned variables; thus reflecting the municipality's propensity to qualify for supplementary transfers. The equilibrium tax rate $\bar{\tau}_{i}^{*}$ depends on $B_{i}^{0}$, while the change in a jurisdiction's tax rate following a reform of the equalization rates is independent of it - see (4). ${ }^{18}$ In section 6.3 we perform sensitivity analysis with respect to the set of covariates summarized in $\mathbf{W}$.

Table 3 provides a summary of the corresponding results for the selection model determining the probability of supplementary transfer eligibility. It turns out that the squared variables are jointly significant and should be included. Six variables enter significantly, irrespective of whether we assume logistically (in the logit) or normally distributed errors (in the probit). In particular, the probability of being treated as supplementary transfer eligible declines with the share of people below working age, and it declines in the pre-treatment level of per-capita income. The likelihood of being treated is higher for regions with large water sheds. The reason is that these regions are relatively remote. For both models, the pseudo $R^{2}$ is fairly high regarding the sample size of 1022 observations and the fairly large number of treated ones, amounting to about 0.26 . The log-likelihood of the logit model is slightly higher than that one of the probit. However, the difference is not significant according to a likelihood ratio test (this test is suggested by Davidson and MacKinnon, 2004). In the subsequent analysis, we use the slightly preferable logit model throughout.

\subsubsection{Switching regression estimates for Lower Saxony}

The second stage results of the switching regression approach are depicted in Table 4. The estimates apply for a randomly selected municipality in

\footnotetext{
${ }^{18}$ Concretely, taking the difference of the equilibrium tax rate before and after the reform (i.e. for different values of $\alpha_{i}$ and $\alpha_{j}$ ), the baseline components $B_{i}^{0}$ and $B_{j}^{0}$ drop out.
} 
the Lower Saxony sample, irrespective of whether it was eligible for supplementary transfers or not. We are primarily interested in the estimates pertaining to the effect of supplementary transfer eligibility. These are to be interpreted as tax rate changes (pre and post reform period) of the eligible municipalities relative to those of non-eligible ones. They correspond to the change in the tax rate gap between eligible and non-eligible municipalities - similar to the illustration in Figure 2. As the pre-reform tax rate we take the 1993/1997 average. Since the fiscal adjustment to the reform might be sluggish, we estimate the corresponding ATE for each post-reform year separately. Also, we check for possible anticipation effects by assigning 1998 to the post-reform period. Recall, the reform became effective as of 1999 after a supreme-court ruling in November 1997.

One concern with treatment estimates is that they might capture the impact of omitted variables. To avoid this problem, we additionally control for covariates in the second stage (outcome) regression. Recall that the matrix of covariates has been referred to as $\mathbf{X}$ in Section 6.1 and, apart from a constant and the endogenous supplementary transfer eligibility in Lower Saxony, it collects the following determinants: the change in population since 1993/1997; the change in population density; the area of streets in hectares; the change in per-capita income since 1993/1997; and the change in the share of elderly people (with an age of more than 65 years).

We have experimented with less parsimonious specifications than the one reported in Table 4. In particular, we have checked for the possible relevance of unemployment rates, and other socio-economic and geographical characteristics accounted for in the selection model. However, it turns out that the less parsimonious model estimates are not significantly preferable to the ones in the table. In particular, population density and the size of the road network are the most important control variables according to their significance.

Similar to the exogenous ATE estimates in Table 2, there is no indication of significant anticipation effects in 1998 with the endogenous treatment approach. Put differently, the identified gap by 2003/2004 between the eligible and non-eligible municipalities is three times larger than its exogenous counterpart. Recall that the reference estimate was about -0.25 percentage points in Table 2 whereas it amounts to -1.20 in the switching regression see Table 4. However, one may argue that most of the difference in the estimates reflects an omitted control variables bias rather than a self-selection bias in Table 2. It turns out that this is not the case. We illustrate this issue in Figure 3. 


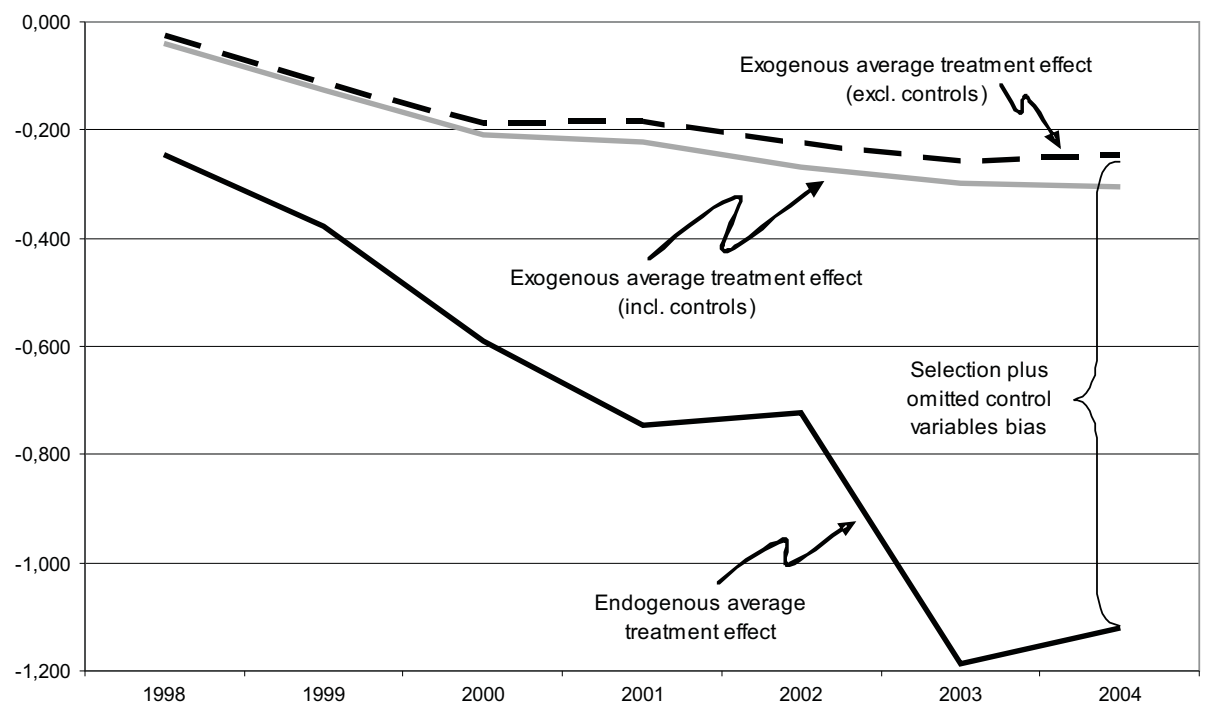

Figure 3: Average treatment effect of being eligible for supplementary transfers on business tax rates in Lower Saxony.

In the figure, the dashed line at the top corresponds to the exogenous simple comparison estimates of the average treatment effect as reported in Table 2. The solid grey one in the middle reflects exogenous treatment effect estimates where the same covariates as in Table 4 have been controlled for. The solid black locus at the bottom of the figure is based on the estimates of the average treatment effect in Table 4. Obviously, the selection bias rather than the omitted variables bias accounts for the lion's share in the difference between the endogenous treatment effect estimates of Table 4 and the exogenous ones in Table 2. Recall that the average level of business tax rates amounted to about 15.5 percent in the pre-reform period and average Lower Saxony municipality. Accordingly, we might say that the reform-induced change in the gap between the eligible and non-eligible communities amounts to almost 10 percent of this level. Note that the constant amounts to somewhat less than 2.4 in the 2004 results in Table 4 . This is an estimate of the change in the average community's business tax rate since 1994/97. Hence, a randomly drawn community's tax rate is increased by about 50 percent less due to supplementary transfer eligibility. The latter is unconditional on whether the community was actually eligible or not. 


\subsection{Matching based on the propensity score}

In the previous analysis, we have focused on ATE, i.e. the treatment effect unconditional on actual treatment status. In fact, this is the (group size) weighted average of the ATT and the average treatment effect of the untreated (ATU). In a next step, we address the effect on the actually treated, i.e. the ATT, by employing different matching estimates of the role of supplementary transfer eligibility for the tax reform effect in Lower Saxony.

Rosenbaum and Rubin (1983) deploy an estimate of the probability of treatment given the covariates $\mathbf{W}$ based on $p(\mathbf{W}) \equiv \operatorname{Prob}(Z=1 \mid \mathbf{W})$. $p(\mathbf{W})$ is the response probability $(\Phi(\mathbf{W} \delta))$, also referred to as the propensity score. $p(\mathbf{W})$ serves as a metric to determine similar observations among the sub-samples of the treated and untreated observations (i.e., to construct a valid control group). Besides ignorability of treatment in the sense of conditional mean-independence, i.e., $E\left(\Delta \tau_{k} \mid \mathbf{W}, Z\right)=E\left(\Delta \tau_{k} \mid \mathbf{W}\right) \forall k=0,1$, the approach of propensity score matching hinges upon the assumption that $0<p(\mathbf{W})<1$ (municipalities outside this support region have to be dropped). ${ }^{19}$ Rosenbaum and Rubin (1983) refer to these two assumptions together as strong ignorability of treatment. In this case, $E[Z(\Delta \tau \mid Z=$ $\left.1, p(\mathbf{W}))]-E[Z(\Delta \tau \mid Z=0, p(\mathbf{W}))]=E\left[Z\left(\Delta \tau_{1}-\Delta \tau_{0}\right) \mid p(\mathbf{W})\right]\right) .{ }^{20} \quad$ With matching, the vector of predicted probabilities of being treated (as supplementary transfer eligible) is used to construct an appropriate control group of ineligible municipalities with a similar probability of being eligible as the actually treated ones.

The most prominent matching procedure is nearest neighbor (or one-toone) matching which works as follows: (i) determine a treated observation's closest 'twin' in terms of the propensity score within the sub-sample of untreated observations; (ii) compute the difference in the scores between the vector of treated and their matched twins; (iii) determine the average difference which is an estimate of ATT. Alternatively, one could do the opposite and match on each untreated observation its closest twin in the sub-sample of treated ones. The latter would give an estimate of the average treatment effect of the ATU (in this case, we subtract the vector of business tax rates

\footnotetext{
${ }^{19}$ Hence, there is an implicit trade-off between goodness of fit in the selection model and the number of observations that can be used for matching.

${ }^{20}$ Note that the use of a single indicator $p(\mathbf{W})$ to determine the similarity of the treatment and control group involves a further assumption: namely that the two groups are not only similar with respect to $p(\mathbf{W})$ but also with respect to each and every determinant collected in $\mathbf{W}$. Otherwise, similarity in $p(\mathbf{W})$ might be an artefact. Hence, matching is only meaningful if we pass a test on the similarity of the observables included in the selection model.
} 
of the matched treated from that one of the untreated). Then, ATE is nothing else than a sub-sample-size-weighted average of ATT and ATU. Hence, propensity score matching overcomes the bias associated with self-selection into treatment by determining a valid control group (see Rosenbaum and Rubin, 1983, 1984, Abadie, 2005, Imbens, 2004) rather than removing the selection bias through the inclusion of inverse Mill's ratios in a switching regression model.

In general, the number of matched control units is either exogenously imposed (such as in the just described one-to-one matching) or a critical interval is determined with all unmatched municipalities in the corresponding probability region around an eligible municipality's predicted probability of being treated. Some estimators even use a large amount or all untreated units as controls with their weight declining in the absolute difference to a treated unit's predicted probability (the latter approach is referred to as kernel matching). In the baseline analysis we resort to nearest neighbor matching and employ alternative matching procedures in the sensitivity analysis.

Nearest neighbor matching is based on the logit estimates in Table 3. The second stage estimates are given in the top panel of Table 5 .

It is obvious that the ATT of the tax rate gap amounts to about -0.27 (in 2002/2004) which is significantly smaller than ATE. This means that an untreated municipality would have set a considerably smaller business tax rate if it had been treated instead. Hence, the ATU is much larger in absolute value than the ATT. The ATT is about as high as the exogenous, biased ATE. But the bias in the exogenous ATE is driven by the underlying ATU.

We report estimates of an alternative matching that involves the Bavarian municipalities as a control group in the bottom panel of Table 5. Within the 1994/2004 period the Bavarian state government kept the equalization rates constant. The results suggest that the ATT in the larger sample is quite similar to its counterpart that is based on Lower Saxony municipalities only. This indicates that the matching quality is fairly good in either of the samples. However, the augmented data set allows us to gauge the exogenous reform effect on the average Lower Saxony municipality besides its interaction effect with supplementary transfer eligibility. This is impossible to infer based on the Lower Saxony data set where other, non-reform effects enter the constant as well. Our findings suggest that the average Lower Saxony municipality had increased its tax rate by 1.16 percentage points by 2003, compared to its Bavarian counterpart. The positive coefficient picks 
up the reform-related incentive effect (some municipalities are hypothesized to increase the tax rate), but also income effects on the average Lower Saxony municipality. Its interpretation may in principle also include significant non-reform-related effects in the state of Bavaria which, however, we are not aware of.

As to the gap in tax rates between eligible and non-eligible municipalities in Lower Saxony, it increased by 0.26 percentage points over the same period in accordance with the theoretical model.

\subsection{Sensitivity analysis}

We considered the robustness of the ATT estimates in several regards. First, even though the balancing property is not violated in our application ${ }^{21}$ one concern might be that the exogenous variables in the selection model have an impact on the change in business tax rates on their own. Then, they should be controlled for in the matching models. Think of matching as a regression that includes a constant and the treatment dummy variable in a sample that consists only of the treated and the control units (this sample would be twice the number of treated observations with nearest neighbor matching). In principle, we can include other controls in this regression as well (see Blundell and Costa Dias, 2002). This is done in the regressions whose results are reported at the top of Table 6 . The included covariates are the same as in Table 3. Note that the results are very similar to those in Table 5. Hence, we can conclude that there is no bias from omitting the corresponding covariates in the second stage regression.

Second, there could be political covariates that could play a role instead. To account for this, we include the shares of the four parties (conservatives, social democrats, liberals, the greens) as possible determinants of changes in the business tax rates. Although some of the political variables enter significantly in the regressions, the results are again very similar to the estimates in Table 5.

Third, we additionally account for the value added tax (VAT) whose rate is set by the federal government, while the proceeds are shared with municipalities. They may be thought of reflecting income effects. Although the VAT enters significantly in some of the regressions, it does not change our estimates of the ATT of the tax reform in Lower Saxony.

\footnotetext{
${ }^{21}$ Hence, the treatment and control group are not different with respect to the explanatory variables in the selection model.
} 
The first bloc of results in Table 6 refers to nonparametric matching procedures such as radius and kernel matching. Note that these rely on a larger sample of control municipalities than nearest neighbor matching. This results in an increase in efficiency but, in finite samples, the matching quality can be seriously smaller than with nearest neighbor matching. However, in our application the difference to the original estimates in Table 6 is negligible. A second bloc of results provides the traditional Heckman (1978) two-step estimates. Note that these are based on a regression where the two Mill's ratios (reported in Table 4) are forced to exhibit the same coefficient. Not surprisingly, these estimates do not differ too much from their ATE counterparts in Table 4. Finally, we apply two instrumental variable procedures suggested by Wooldridge (2002); i.e. Procedure 18.1 and a variant of Procedure 18.3. In contrast to the matching and the switching regression model, instrumental variable procedures rest on relatively weaker assumptions regarding the available observable variables. However, they require the existence of identifying instruments that are correlated with the selection indicator (the supplementary transfer eligibility), but not directly with the outcome (the change in business tax rates). As explained above, the variables which are most notably uncorrelated with the outcome of the second-stage regression are the geographical variables of the first-stage regression. It turns out that the corresponding ATE estimates are very similar to the previous ones - see Table 6 .

We undertake the same sensitivity analysis for the estimates that are based on Lower Saxony and Bavaria - see Table 7. In general, the results are similarly robust as the previous ones (note that the bloc of results at the top of Table 7 should be compared to the ones in the bottom panel of Table 5). However, with the larger sample of Bavarian control units the non-parametric (radius and kernel) matching estimators obviously lose in quality and cannot recommended any longer. Otherwise, the results are generally very robust in all considered respects.

In a final set of experiments, we change the specification of the probit model to investigate the sensitivity of the results in that regard. In Table 8 we consider Lower Saxony municipalities only, and the results in Table 9 are again based on the augmented sample including Bavarian municipalities in addition. In this analysis, we confine ourselves to two representative estimators: one-to-one matching as far as ATT is concerned, and Wooldridge's Procedure 18.1 instrumental variable estimator regarding ATE.

We estimate three alternative probit models. The first one represents a rigorous second-order polynomial rather than only main effects and their 
squared values as in Table 3 . Hence, this specification also includes a comprehensive set of interaction terms of the main effects as suggested by Rosenbaum and Rubin (1983). A second model only includes variables that are strictly exogenous, at least in the medium run: namely the geographical variables such as agricultural land, forest land, and watersheds (simple and squared values thereof). ${ }^{22}$ The third variant only relies upon population and income variables variables in the pre-reform period: population, density, income per capita, and the share of people with an age of less than 15 years. With the specification based on geographical variables we obtain parameter estimates larger in absolute value than in the original specifications. However, the general pattern of the estimated effects resembles the reference estimates.

An alternative way to deal with potential self-selection is to limit the econometric analysis to those municipalities for which the problem is less of a concern, i.e. which operate not too close to the kind $D$ of the transfer formula - see Figure 1. Constructing the treatment group, we exclude all municipalities that were potentially able to affect their eligibility status. We define these municipalities as ones that had a lower ratio of the critical-toactual fiscal capacity ratio than the average transfer receiving municipality (the critical fiscal capacity is centrally determined). Among the group of non-recipients, we treat those units as potentially being able to affect their eligibility status that had a higher ratio than the average non-recipient unit. After excluding these municipalities in each year, we estimate the regression model underlying the results in Table 4 . We obtain insignificant parameter estimates of 0.027 and -0.099 for 1998 and 1999, respectively. The parameter estimates for the years $2000-2004$ are $-0.148,-0.150,-0.206,-0.327$, and 0.296. The estimates are significant at least at the five percent level. The size and pattern of the results is remarkably similar to the matching estimates in Table 7.

\section{Conclusion}

Capacity equalization grants have been adopted in many countries primarily to affect interregional equity - but they may nevertheless influence local

\footnotetext{
${ }^{22} \mathrm{~A}$ reason for restricting the number of covariates in the binary choice model is that matching estimators include a bias term that declines at stochastic order $(N-1) / k$, with $N$ being the number of observations and $k$ denoting the number of observables in the selection model. In small samples, this bias can be fairly large (see Frölich, 2004, Abadie and Imbens, 2006). With instrumental variable estimation, there is no presumption to rely on a large number of identifying instruments, anyway.
} 
policy incentives and the efficiency of the equilibrium tax system. Equalization grants calculate transfer entitlements indirectly, using differences in revenues calculated at deemed rather than actual tax rates. But when measured tax bases respond negatively to tax rate increases, this formula may induce higher levels of taxation: increasing local tax rates causes measured tax bases to decline, as economic activity shifts to other regions of the country or to other, more lightly taxed forms - and so causes capacity equalization transfers to rise. Thus the grants in effect subsidize increases in taxes by equalization-receiving governments.

The paper empirically analyzes the incentive effects of equalizing transfers on business tax policy by exploiting a natural experiment in the state of Lower Saxony which changed its equalization formula as of 1999. Relying on within-state and across-state difference-in-difference estimates, the analysis reveals a significant impact of the reform on municipalities' tax policy in the four years after the reform with a "phasing out" of the effect starting in the fourth to fifth year. The finding is robust to various alternative specifications. The empirical result is in line with the theoretical prediction of a positive incentive effect of equalization grants on local tax rates.

From a policy perspective, the analysis suggests that fiscal capacity equalization implicitly acts as a tax coordination scheme, which deters municipalities from lowering taxes in order to attract a larger tax base (since it would result in a reduction in transfers) and which therefore mitigates fiscal competition. ${ }^{23}$ Our reduced form approach does not allow us to determine the extent to which the tax-raising effect of equalization is in fact mitigated by the effects of fiscal competition among German municipalities that would otherwise have reduced consumer welfare. But this interpretation is in line with the observation that the federal corporate tax rate fell from $56 \%$ on retained earnings and $36 \%$ on distributed earnings in 1980 to a uniform rate of $26.25 \%$ as of 2001 (in successive tax-cut cum base-broadening reforms), a trend that is often attributed to intensified fiscal competition. On the other hand, municipal business tax rates on average did not fell over the same period, suggesting that some mechanism - perhaps equalization grants - insulates these jurisdictions from fiscal competition. ${ }^{24}$

\footnotetext{
${ }^{23}$ Indeed, Köthenbürger (2002) and Bucovetsky and Smart (2006) show that, in the presence of horizontal tax competition, equalization grant may in a wide variety of settings induce subnational governments to independently choose tax rates that increase welfare.

${ }^{24}$ The federal corporate tax base is nearly perfectly co-occupied by the municipalities' business tax such that the broadening of the tax base does not account for the asymmetric response.
} 


\section{References}

[1] Abadie, A. (2005), Semiparametric Difference-in-Differences Estimators, Review of Economic Studies 72(1), 1-19.

[2] Abadie, A. and G. Imbens (2006), Large Sample Properties of Matching Estimators for Average Treatment Effects, Econometrica 74(1), 235267.

[3] Baretti, C., B. Huber and K. Lichtblau (2002), A Tax on Tax Revenue: The Incentive Effects of Equalizing Transfers: Evidence from Germany, International Tax and Public Finance 9(6), 631-649.

[4] Blundell, R. and M. Costa Dias (2002), Alternative Approaches to Evaluation in Empirical Microeconomics, Portuguese Economic Review 1, 91-115.

[5] Bucovetsky, S. (1991), Asymmetric Tax Competition, Journal of Urban Economics 30(2), 167-181.

[6] Bucovetsky, S. and M. Smart (2006), The Efficiency Consequences of Local Revenue Equalization: Tax Competition and Tax Distortions, Journal of Public Economic Theory 8(1), 119-144.

[7] Buettner, T. (2006), The Incentive Effects of Fiscal Equalization Transfers on Tax Policy, Journal of Public Economics 90(3), 477-497.

[8] Cameron, A.C. and K.R. Trivedi (2005), Microeconometrics: Methods and Applications, Cambridge University Press, New York.

[9] Dahlby, B., and N.A. Warren (2003), The Fiscal Incentive Effects of the Australian Equalisation System, Economic Record 79(247), 434-445.

[10] Davidson, R. and J.G. MacKinnon (2004), Econometric Theory and Methods, University Press, Oxford.

[11] Frölich, M. (2004), Programme Evaluation with Multiple Treatments, Journal of Economic Surveys 18, 181-224.

[12] Hayashi M. and R. Boadway (2001), An Empirical Analysis of Intergovernmental Tax Interaction: The Case of Business Income Taxes in Canada, Canadian Journal of Economics 34, 481-503. 
[13] Heckman, J.J. (1978), Dummy Endogenous Variables in a Simultaneous Equation System, Econometrica 46(4), 931-959.

[14] Heckman, J.J. and R. Richard Jr. (1985), Alternative Methods of Evaluating the Impact of Interventions, in: James J. Heckman (ed.), Longitudinal Analysis of Labour Market Data, Econometric Society Monographs series, no. 10, Cambridge University Press, New York, 156-245.

[15] Imbens, G. (2004), Nonparametric Estimation of Average Treatment Effects Under Exogeneity: A Review, Review of Economics and Statistics 86(1), 4-29.

[16] Köthenbürger, M. (2002), Tax Competition and Fiscal Equalization, International Tax and Public Finance 9(4), 391-408.

[17] Moffitt, R. A. (1996), Identification of Causal Effects Using Instrumental Variables: Comment, Journal of the American Statistical Association 91, 462-465.

[18] Rosenbaum, P.R. and D.B. Rubin (1983), The Central Role of the Propensity Score in Observational Studies for Causal Effects, Biometrika 70(1), 41-55.

[19] Rosenbaum, P.R. and D.B. Rubin (1984), Reducing Bias in Observational Studies Using Subclassification on the Propensity Score, Journal of the American Statistical Association 79(387), 516-524.

[20] Smart, M. (1998), Taxation and Deadweight Loss in a System of Intergovernmental Transfers, Canadian Journal of Economics 31(1), 189-206.

[21] Smart, M. (2006), Raising taxes through Equalization, Working Paper, University of Toronto.

[22] Wooldridge J.M. (2002), Econometric Analysis of Cross Section and Panel Data, MIT Press, Cambridge, MA. 
Table 1 - Descriptive statistics Lower Saxony

\begin{tabular}{lccc}
\hline & Supplementary transfer eligibility in at leat one year of \\
& \multicolumn{3}{c}{$1994-98$} \\
Number of municipalities & Eligible & Non-eligible & All \\
Business tax rate in percent (mean) & 748 & 274 & 1022 \\
Fiscal capacity per capita in Euros (mean) & 15,51 & 15,63 & 15,54 \\
Income per capita in Euros per annum (mean) & 333,54 & 466,59 & 369,21 \\
\hline
\end{tabular}


Table 2 - Descriptive comparison of change in business tax rates for supplementary transfer eligible municipalities versus non-eligible ones in Lower Saxony (Reported estimates are with respect to changes as compared to 1994-1997 average levels)

\begin{tabular}{|c|c|c|c|c|c|c|c|}
\hline & 1998 & 1999 & 2000 & 2001 & 2002 & 2003 & 2004 \\
\hline Supplementary transfer eligibility in Lower Saxony & $-0,026$ & $-0,116 * \star$ & $-0,188 * \star \star$ & $-0,184^{\star \star \star}$ & $-0,224 * \star \star$ & $-0,258 * \star \star$ & $-0,249 * \star \star$ \\
\hline & 0,042 & 0,047 & 0,051 & 0,057 & 0,070 & 0,078 & 0,080 \\
\hline Constant & $\begin{array}{l}0,412 \\
0,036\end{array}$ & $\begin{array}{l}0,548 \\
0,041\end{array}$ & $\begin{array}{l}0,698 \text { *** } \\
0,044\end{array}$ & $\begin{array}{l}0,817 \\
0,050\end{array}$ & $\begin{array}{l}1,059 \\
0,062\end{array}$ & $\begin{array}{l}1,280 \\
0,068\end{array}$ & $\begin{array}{l}1,449 \\
0,071\end{array}$ \\
\hline
\end{tabular}

${ }_{\star \star \star}$ significant at 1 percent; ${ }^{\star \star}$ significant at 5 percent. 
Table 3 - Selection into supplementary transfer eligibility (Lower Saxony)

\begin{tabular}{|c|c|c|}
\hline & Logit & Probit \\
\hline \multirow{2}{*}{ Agricultural land as of 1993 (in ha) } & $-2,515$ & $-1,522$ \\
\hline & 2,942 & 1,713 \\
\hline \multirow[t]{2}{*}{ Forest as of 1993 (in ha) } & 0,769 & 0,341 \\
\hline & 2,742 & 1,597 \\
\hline \multirow[t]{2}{*}{ Water as of 1993 (in ha) } & $40,824 * \star \star$ & $24,545 * \star \star$ \\
\hline & 11,338 & 6,607 \\
\hline \multirow{2}{*}{ Streets as of 1993 (in ha) } & 2,121 & 1,010 \\
\hline & 5,570 & 3,164 \\
\hline \multirow[t]{2}{*}{ Per-capita income as of 1993} & 0,001 & 0,000 \\
\hline & 0,001 & 0,000 \\
\hline \multirow[t]{2}{*}{ Population size as of 1993} & 0,000 & 0,000 \\
\hline & 0,000 & 0,000 \\
\hline \multirow[t]{2}{*}{ Population density as of 1993} & 0,198 & 0,098 \\
\hline & 0,167 & 0,096 \\
\hline \multirow[t]{2}{*}{ Population share with age $\leq 15$ as of 1993} & $-95,616 * \star \star$ & $-55,447 * \star \star$ \\
\hline & 34,098 & 19,698 \\
\hline \multirow[t]{2}{*}{ Square of agricultural land as of (in ha) } & 3,457 & 1,996 \\
\hline & 3,190 & 1,860 \\
\hline \multirow[t]{2}{*}{ Square of forest as of (in ha) } & $-0,590$ & $-0,262$ \\
\hline & 3,847 & 2,250 \\
\hline \multirow[t]{2}{*}{ Square of water as of (in ha) } & $-341,586 * * *$ & $-205,735 * * *$ \\
\hline & 115,924 & 66,437 \\
\hline \multirow{2}{*}{ Square of streets as of (in ha) } & 0,276 & 0,138 \\
\hline & 12,558 & 7,130 \\
\hline \multirow[t]{2}{*}{ Square of per-capita income as of 1993} & $-8,19 \mathrm{E}-08$ * & $-3,36 \mathrm{E}-08$ * \\
\hline & 3,82E-08 & 2,03E-08 \\
\hline \multirow[t]{2}{*}{ Square of population size as of 1993} & $1,59 \mathrm{E}-11$ & $9,16 \mathrm{E}-12$ \\
\hline & $5,20 \mathrm{E}-11$ & $2,72 \mathrm{E}-11$ \\
\hline \multirow[t]{2}{*}{ Square of population density as of 1993} & $-0,014$ & $-0,007$ \\
\hline & 0,019 & 0,010 \\
\hline \multirow[t]{2}{*}{ Square of population share with age $\leq 15$ as of 1993} & $289,766 * \star \star$ & $168,152 * \star \star$ \\
\hline & 94,544 & 54,521 \\
\hline \multirow[t]{2}{*}{ Constant } & 7,093 * & 5,107 ** \\
\hline & 3,981 & 2,240 \\
\hline Pseudo $\mathrm{R}^{2}$ & 0,256 & 0,255 \\
\hline Log-likelihood & $-471,962$ & $-473,152$ \\
\hline Joint exclusion of squares (LR-test statistic) & 34,791 & 33,485 \\
\hline P-value & 0,000 & 0,000 \\
\hline Probit vs. Logit (LR-test statistic) & & \\
\hline P-value & & \\
\hline
\end{tabular}

*** significant at 1 percent; ${ }^{* *}$ significant at 5 percent; * significant at 10 percent. 
Table 4 - Endogenous average treatment effect of supplementary transfer eligibility on the change in business tax rates in Lower Saxony (Reported estimates are with respect to changes as compared to 1994-1997 average levels)

\begin{tabular}{|c|c|c|c|c|c|c|c|}
\hline Explanatory variables & 1998 & 1999 & 2000 & 2001 & 2002 & 2003 & 2004 \\
\hline \multirow[t]{2}{*}{ Supplementary transfer eligibility in Lower Saxony } & $-0,245$ & $-0,379 \star \star$ & $-0,590$ ** & 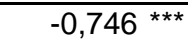 & $-0,723$ ** & $-1,187^{\star \star \star}$ & 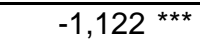 \\
\hline & 0,216 & 0,231 & 0,268 & 0,301 & 0,356 & 0,395 & 0,443 \\
\hline \multirow{2}{*}{ Change in population since 1993/1997 } & 0,00001 & 0,00002 & $-0,00001$ & $-0,00005$ & $-0,00004$ & $-0,000001$ & 0,000004 \\
\hline & 0,0001 & 0,0000 & 0,00004 & 0,00004 & 0,00004 & 0,00004 & 0,000042 \\
\hline \multirow[t]{2}{*}{ Population density } & $-0,020$ & $-0,018$ & $-0,039 * *$ & $-0,062 * * *$ & $-0,071 * * *$ & $-0,098 * * *$ & $-0,111 * * *$ \\
\hline & 0,014 & 0,015 & 0,017 & 0,019 & 0,024 & 0,026 & 0,029 \\
\hline \multirow[t]{2}{*}{ Streets (in ha) } & $-0,7786 * \star$ & $-0,9900 * \star *$ & $-1,0126 * \star \star$ & $-1,4397 * \star \star$ & $-1,2055 * \star$ & $-0,7927$ & $-1,1143$ \\
\hline & 0,3364 & 0,3525 & 0,3533 & 0,3901 & 0,5863 & 0,7429 & 0,7764 \\
\hline \multirow[t]{2}{*}{ Change in per-capita income since $1993 / 1997$} & $-0,00001$ & $-0,00001$ & $-0,000003$ & 0,00001 & 0,00002 & 0,00002 & $-0,00001$ \\
\hline & 0,00001 & 0,00001 & 0,00001 & 0,00002 & 0,00002 & 0,00003 & 0,00004 \\
\hline \multirow[t]{2}{*}{ Change in share of elderly people (age $>65$ ) } & 3,3788 & $4,6107 * \star$ & 1,6898 & 2,3633 & $-1,1735$ & $-1,9377$ & $-2,5617$ \\
\hline & 2,5616 & 2,1210 & 2,0142 & 2,1867 & 2,1839 & 2,2878 & 2,1673 \\
\hline \multirow[t]{2}{*}{ Constant } & $0,683 * \star *$ & $0,857 * \star \star$ & $1,162 * \star \star$ & 1,468 *** & $1,624 * * *$ & $2,193 * * *$ & $2,357 * \star \star$ \\
\hline & 0,207 & 0,221 & 0,257 & 0,289 & 0,345 & 0,380 & 0,433 \\
\hline \multirow[t]{2}{*}{ Inverse Mills' ratio of treated } & 0,042 & 0,019 & 0,067 & 0,073 & 0,217 & $0,473 * *$ & $0,575 * *$ \\
\hline & 0,124 & 0,136 & 0,151 & 0,182 & 0,218 & 0,241 & 0,256 \\
\hline \multirow[t]{2}{*}{ Inverse Mills' ratio of untreated } & 0,161 & 0,206 & 0,301 * & $0,429 * \star$ & 0,323 & $0,595 * *$ & 0,494 * \\
\hline & 0,155 & 0,164 & 0,188 & 0,209 & 0,253 & 0,277 & 0,312 \\
\hline
\end{tabular}

Notes: Reported figures are instrumental variable based estimated changes as compared to 1994-1997 average levels. Supplementary transfer eligibility in Lower Saxony is endogenous.

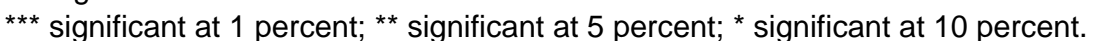


Table 5 - Endogenous average treatment effect of the supplementary transfer treated on the change in business tax rates in Lower Saxony

(Reported estimates are propensity score nearest neighbor matching based with respect to changes as compared to 1994-1997 average levels)

\begin{tabular}{|c|c|c|c|c|c|c|c|}
\hline & 1998 & 1999 & 2000 & 2001 & 2002 & 2003 & 2004 \\
\hline & \multicolumn{7}{|c|}{ Lower Saxonian municipalities only } \\
\hline \multirow{3}{*}{$\begin{array}{l}\text { Supplementary transfer eligibility in Lower Saxony } \\
\text { (incl. controls as in Table 4) }\end{array}$} & $-0,016$ & $-0,069$ & 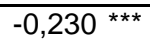 & $-0,189 * \star$ & $-0,267 \star \star$ & $-0,294 * \star \star$ & $-0,258 * \star \star$ \\
\hline & 0,067 & 0,070 & 0,071 & 0,082 & 0,108 & 0,059 & 0,115 \\
\hline & \multicolumn{7}{|c|}{ Lower Saxonian and Bavarian municipalities } \\
\hline \multirow{2}{*}{$\begin{array}{l}\text { Supplementary transfer eligibility in Lower Saxony } \\
\text { (incl. controls as in Table 4) }\end{array}$} & $-0,056$ & $-0,078$ * & $-0,182 * \star \star$ & $-0,229 \star \star \star$ & $-0,246 * \star \star$ & $-0,265$ *** & $-0,263 * \star \star$ \\
\hline & 0,042 & 0,045 & 0,048 & 0,057 & 0,067 & 0,074 & 0,078 \\
\hline Lower Saxony dummy & $0,419 * * *$ & $0,432 * \star \star$ & $0,615 * * *$ & 0,748 *** & $0,957 * \star \star *$ & $1,090 * \star *$ & 1,162 *** \\
\hline (incl. controls as in Table 4) & 0,046 & 0,048 & 0,052 & 0,062 & 0,073 & 0,080 & 0,084 \\
\hline
\end{tabular}

0,073

0,080

$1,162 * \star *$

Notes: Reported estimates are propensity score nearest neighbor matching based with respect to changes as compared to 1994-1997 average levels. Supplementary transfer eligibility in Lower Saxony is endogenous.

*** significant at 1 percent; ** significant at 5 percent; * significant at 10 percent. 
Table 6 - Sensitivity analysis (Lower Saxonian municipalities only)

(Reported estimates are changes as compared to 1994-1997 average levels)

\begin{tabular}{|c|c|c|c|c|c|c|c|}
\hline & 1998 & 1999 & 2000 & 2001 & 2002 & 2003 & 2004 \\
\hline \multicolumn{8}{|l|}{ Matching estimators (ATT): } \\
\hline $\begin{array}{l}\text { Nearest neighbor matching } \\
\text { (incl. controls as in Table 4) }\end{array}$ & $\begin{array}{r}-0,015 \\
0,039\end{array}$ & $\begin{array}{c}-0,073 * \\
0,042\end{array}$ & $\begin{array}{l}-0,232 * \star * \\
0,046\end{array}$ & $\begin{array}{l}-0,196 * * * \\
0,050\end{array}$ & $\begin{array}{l}-0,270^{* * *} \\
0,063\end{array}$ & $\begin{array}{l}-0,291 * * * \\
0,068\end{array}$ & $\begin{array}{l}-0,257 * * * \\
0,069\end{array}$ \\
\hline $\begin{array}{l}\text { Nearest neighbor matching } \\
\text { (incl. controls as before plus political variables) }\end{array}$ & $\begin{array}{r}-0,019 \\
0,039\end{array}$ & $\begin{array}{l}-0,073 \text { * } \\
0,042\end{array}$ & $\begin{array}{l}-0,232 \text { *** } \\
0,046\end{array}$ & $\begin{array}{l}-0,195 * * * \\
0,050\end{array}$ & $\begin{array}{l}-0,270 * * * \\
0,063\end{array}$ & $\begin{array}{l}-0,291 * * * \\
0,067\end{array}$ & $\begin{array}{l}-0,258 * * * \\
0,068\end{array}$ \\
\hline $\begin{array}{l}\text { Nearest neighbor matching } \\
\text { (incl. controls as before plus change in VAT) }\end{array}$ & $\begin{array}{r}-0,019 \\
0,039\end{array}$ & $\begin{array}{l}-0,090 * * \\
0,043\end{array}$ & $\begin{array}{l}-0,246 \text { *** } \\
0,046\end{array}$ & $\begin{array}{l}-0,200 * * * \\
0,050\end{array}$ & $\begin{array}{l}-0,280 * * * \\
0,063\end{array}$ & $\begin{array}{l}-0,302 \text { *** } \\
0,067\end{array}$ & $\begin{array}{l}-0,272 * * * \\
0,069\end{array}$ \\
\hline $\begin{array}{l}\text { Caliper matching } \\
\text { (radius is } 0.1 \text { - incl. controls as in Table } 4)\end{array}$ & $\begin{array}{r}-0,039 \\
0,039\end{array}$ & $\begin{array}{l}-0,135 * * * \\
0,042\end{array}$ & $\begin{array}{l}-0,207^{* * *} \\
0,045\end{array}$ & $\begin{array}{l}-0,199 * * * \\
0,050\end{array}$ & $\begin{array}{l}-0,260 * * * \\
0,063\end{array}$ & $\begin{array}{l}-0,270^{* * *} \\
0,068\end{array}$ & $\begin{array}{l}-0,267 * * * \\
0,070\end{array}$ \\
\hline $\begin{array}{l}\text { Kernel matching } \\
\text { (epanechnikov kernel with bandwidth of } 0.8 \text { - incl. controls as in Table } 4)\end{array}$ & $\begin{array}{r}-0,032 \\
0,038 \\
\end{array}$ & $\begin{array}{l}-0,121 * * * \\
0,042\end{array}$ & $\begin{array}{l}-0,196 * * \\
0,044\end{array}$ & $\begin{array}{l}-0,182 * * \\
0,050\end{array}$ & $\begin{array}{l}-0,244 * * * \\
0,063\end{array}$ & $\begin{array}{l}-0,247 * * * \\
0,068\end{array}$ & $\begin{array}{l}-0,257^{* * *} \\
0,069\end{array}$ \\
\hline $\begin{array}{l}\text { Heckman (1978) estimator (ATE): } \\
\quad \text { (first stage as in Table 2; second stage as in Table } 4 \text { plus inverse Mill's ratio) }\end{array}$ & $\begin{array}{l}-0,199 \\
0,197 \\
\end{array}$ & $\begin{array}{r}-0,304 \\
0,213 \\
\end{array}$ & $\begin{array}{l}-0,495^{* *} \\
0,229\end{array}$ & $\begin{array}{l}-0,6022^{* *} \\
0,261\end{array}$ & $\begin{array}{l}-0,680^{* *} \\
0,318\end{array}$ & $\begin{array}{l}-1,137^{* * *} \\
0,363\end{array}$ & $\begin{array}{l}-1,1544^{* \star *} \\
0,376\end{array}$ \\
\hline \multicolumn{8}{|l|}{ 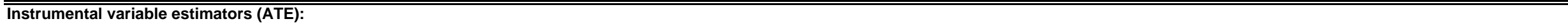 } \\
\hline $\begin{array}{l}\text { Wooldridge's (2002, p. 623) Procedure } 18.1 \\
\text { (first stage as in Table 2; second stage as in Table } 4 \text { plus } \Phi(\mathbf{W} \delta))^{\text {a) }}\end{array}$ & $\begin{array}{r}-0,182 \\
0,191\end{array}$ & $\begin{array}{r}-0,256 \\
0,213\end{array}$ & $\begin{array}{l}-0,419 \text { * } \\
0,244\end{array}$ & $\begin{array}{l}-0,509 \text { * } \\
0,276\end{array}$ & $\begin{array}{l}-0,632 \text { * } \\
0,326\end{array}$ & $\begin{array}{l}-1,066 \text { *** } \\
0,391\end{array}$ & $\begin{array}{l}-1,171 \text { *** } \\
0,430\end{array}$ \\
\hline $\begin{array}{l}\text { Wooldridge's (2002, p. 629) Procedure } 18.3 \\
(\text { first stage as in Table } 2 \text { plus } \phi(\mathbf{W} \delta) \text { and } \Phi(\mathbf{W} \delta) \text {; second stage as in Table } 4 \text { plus } \phi(\mathbf{W} \delta))^{\text {a) }}\end{array}$ & $\begin{array}{r}-0,179 \\
0,188\end{array}$ & $\begin{array}{r}-0,254 \\
0,208\end{array}$ & $-0,416$ * & $\begin{array}{l}-0,508 \text { * } \\
0,274\end{array}$ & $\begin{array}{l}-0,631 * * \\
0,320\end{array}$ & $\begin{array}{l}-1,075 * * \star \\
0,379\end{array}$ & $\begin{array}{l}-1,187 * * * \\
0,411\end{array}$ \\
\hline
\end{tabular}

0,508

$-1,075$
0,379

0,411

a) $\phi(\mathbf{W} \delta)$ and $\Phi(\mathbf{W} \delta)$ are the density and joint density, respectively, evaluated at the estimated parameter vector $\delta$ in the probit model.

*** significant at 1 percent; ** significant at 5 percent; * significant at 10 percent. 
Table 7 - Sensitivity analysis (Lower Saxonian and Bavarian municipalities; all estimators as in Table 5 plus Lower Saxony dummy) (Reported estimates are changes as compared to 1994-1997 average levels)

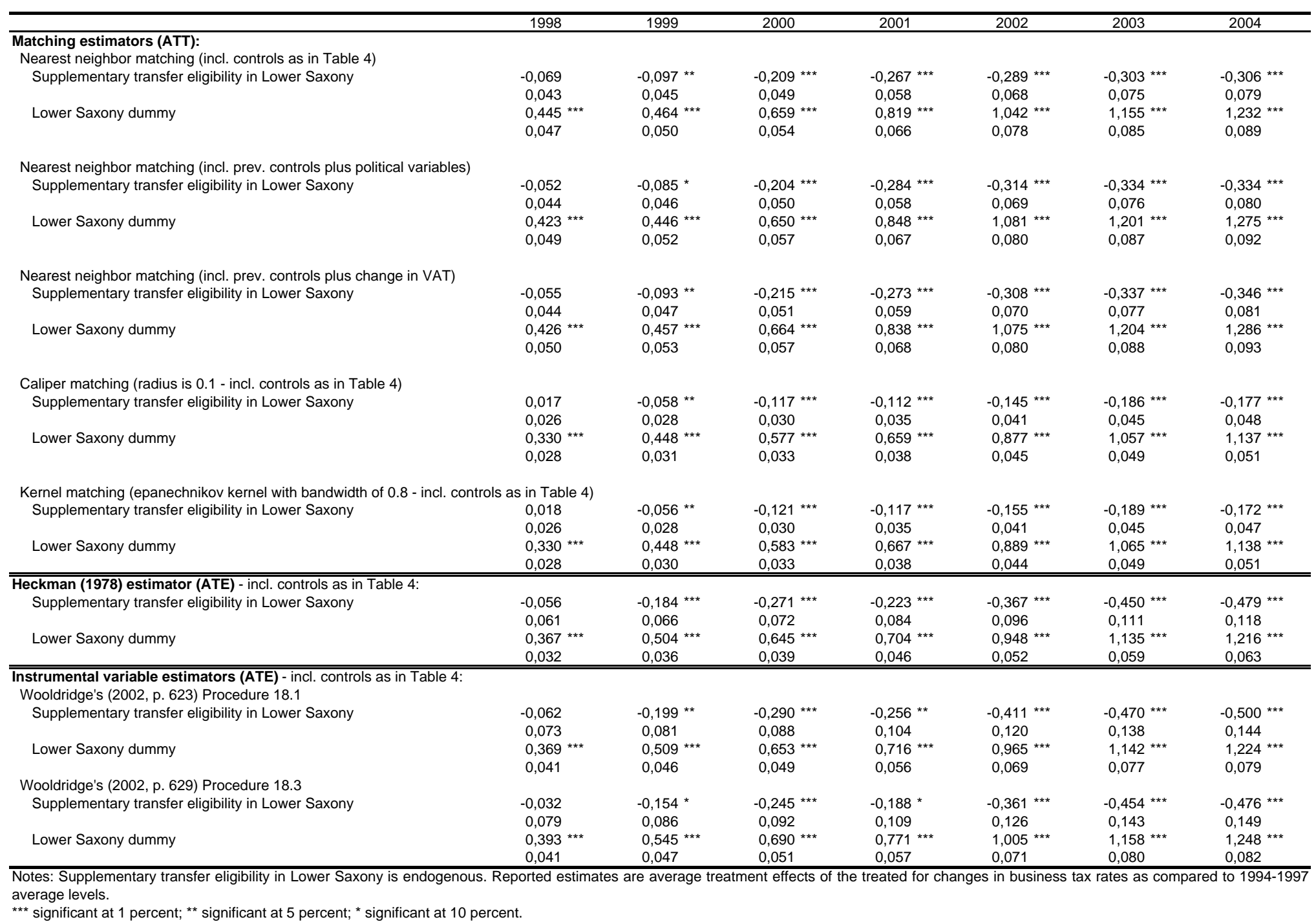


Table 8 - Sensitivity analysis with respect to specification of the probit model (Lower Saxonian municipalities only)

(Reported estimates are changes as compared to 1994-1997 average levels)

\begin{tabular}{|c|c|c|c|c|c|c|c|}
\hline Probit specification & 1998 & 1999 & 2000 & 2001 & 2002 & 2003 & 2004 \\
\hline \multicolumn{8}{|c|}{ Nearest neighbor matching (ATT) - incl. controls as in Table 4: } \\
\hline \multirow[t]{2}{*}{ Probit specification $A^{\text {a) }}$} & $-0,483$ & $-0,527$ & $-0,875$ & $-1,160$ & $-1,462$ & $-2,797 * *$ & $-3,130 * *$ \\
\hline & 0,575 & 0,636 & 0,734 & 0,835 & 0,986 & 1,172 & 1,282 \\
\hline \multirow[t]{2}{*}{ Probit specification $\mathrm{B}^{\mathrm{b})}$} & $-0,675$ & $-0,699$ & $-1,153$ & $-1,554$ & $-1,973$ & $-3,868 * \star$ & $-4,335 * *$ \\
\hline & 0,817 & 0,900 & 1,056 & 1,204 & 1,420 & 1,692 & 1,841 \\
\hline \multirow[t]{2}{*}{ Probit specification $C^{c}$ ) } & $-0,951$ & $-0,937$ & $-1,577$ & $-2,162$ & $-2,738$ & $-5,462 * *$ & $-6,152 * *$ \\
\hline & 1,193 & 1,318 & 1,497 & 1,697 & 2,026 & 2,442 & 2,621 \\
\hline \multicolumn{8}{|c|}{ "Wooldridge's (2002, p. 623) Procedure 18.1 (ATE) - incl. controls as in Table 4: } \\
\hline \multirow[t]{2}{*}{ Probit specification $A^{a)}$} & $-0,035$ & $-0,158 * \star *$ & $-0,225 * \star *$ & $-0,216 * \star *$ & $-0,296 * \star \star$ & $-0,372 * \star *$ & $-0,398 * * *$ \\
\hline & 0,039 & 0,044 & 0,046 & 0,050 & 0,065 & 0,072 & 0,072 \\
\hline \multirow[t]{2}{*}{ Probit specification $\mathrm{B}^{\mathrm{b}}$ ) } & $-0,005$ & $-0,071$ * & $-0,140 * \star *$ & $-0,159 * \star *$ & $-0,234 * \star *$ & $-0,212 * * *$ & $-0,247 * * *$ \\
\hline & 0,038 & 0,041 & 0,043 & 0,049 & 0,063 & 0,067 & 0,070 \\
\hline \multirow[t]{2}{*}{ Probit specification $\mathrm{C}^{\mathrm{c})}$} & $-0,087$ * & $-0,189 * * *$ & $-0,276 * \star \star$ & $-0,276 * \star \star$ & $-0,309 * * *$ & $-0,377 * * *$ & $-0,451 * * *$ \\
\hline & 0,040 & 0,044 & 0,046 & 0,052 & 0,062 & 0,070 & 0,073 \\
\hline
\end{tabular}

Notes: Supplementary transfer eligibility in Lower Saxony is endogenous. Reported estimates are average treatment effects of the treated for changes in business tax rates as compar

a) Full second-order polynomial function: probit specification as in Table 2 plus interaction terms among the non-squared regressors

b) Probit specification that only includes the following variables measuring area in hectares: agricultural land, forest land, watersheds, and theirsquared values.

c) Probit specification that only includes per-capita income as of 1993, population as of 1993, population density as of 1993 , and the population share with age $<15$ as of 1993 .

*** significant at 1 percent; ** significant at 5 percent; * significant at 10 percent. 
Table 9 - Sensitivity analysis with respect to specification of the probit model (Lower Saxonian and Bavarian municipalities) (Reported estimates are changes as compared to 1994-1997 average levels)

\begin{tabular}{|c|c|c|c|c|c|c|c|}
\hline Probit specification & 1998 & 1999 & 2000 & 2001 & 2002 & 2003 & 2004 \\
\hline \multicolumn{8}{|c|}{ 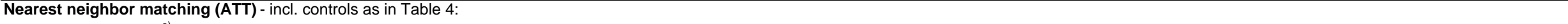 } \\
\hline \multicolumn{8}{|l|}{ Probit specification $A^{\text {a) }}$} \\
\hline \multirow[t]{2}{*}{ Supplementary transfer eligibility in Lower Saxony } & $-0,027$ & $-0,136 * \star *$ & $-0,229 * \star \star$ & $-0,119 *$ & $-0,140$ * & $-0,183 * \star$ & $-0,137$ \\
\hline & 0,044 & 0,048 & 0,051 & 0,061 & 0,073 & 0,082 & 0,086 \\
\hline \multirow[t]{2}{*}{ Lower Saxony dummy } & $0,368 \quad * * *$ & $0,510 * * *$ & $0,687 * * *$ & $0,672 \quad * * *$ & $0,889 * * *$ & $1,034 * * *$ & $1,046 * \star \star$ \\
\hline & 0,052 & 0,057 & 0,060 & 0,065 & 0,079 & 0,088 & 0,092 \\
\hline \multicolumn{8}{|l|}{ Probit specification $\mathrm{B}^{\mathrm{b})}$} \\
\hline \multirow[t]{2}{*}{ Supplementary transfer eligibility in Lower Saxony } & $-0,026$ & $-0,123$ ** & $-0,275 * \star \star$ & $-0,294 * * *$ & $-0,438 * \star \star$ & $-0,434$ *** & $-0,439 * * *$ \\
\hline & 0,048 & 0,052 & 0,058 & 0,066 & 0,078 & 0,085 & 0,089 \\
\hline \multirow[t]{2}{*}{ Lower Saxony dummy } & $0,365 * \star \star *$ & $0,494 * * *$ & $0,705 * \star \star *$ & 0,817 *** & $1,159 * \star \star$ & 1,314 *** & $1,326 * \star *$ \\
\hline & 0,050 & 0,054 & 0,060 & 0,070 & 0,083 & 0,091 & 0,096 \\
\hline \multicolumn{8}{|l|}{ Probit specification $C^{c)}$} \\
\hline \multirow{2}{*}{ Supplementary transfer eligibility in Lower Saxony } & 0,018 & $-0,112$ ** & $-0,154 \star \star \star *$ & $-0,221 * * *$ & $-0,252 * \star \star$ & $-0,311 * \star \star$ & $-0,324 * \star \star$ \\
\hline & 0,046 & 0,051 & 0,055 & 0,057 & 0,070 & 0,076 & 0,078 \\
\hline \multirow{2}{*}{ Lower Saxony dummy } & 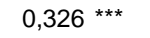 & $0,476 * \star *$ & 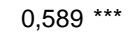 & $0,797 * \star \star$ & $1,018 * \star \star$ & $1,232 * \star \star *$ & 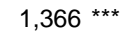 \\
\hline & 0,048 & 0,054 & 0,058 & 0,067 & 0,083 & 0,090 & 0,092 \\
\hline \multicolumn{8}{|c|}{ 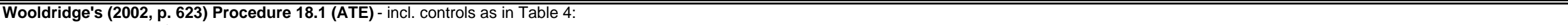 } \\
\hline \multicolumn{8}{|c|}{ Probit specification $A^{\text {a) }}$} \\
\hline \multirow[t]{2}{*}{ Supplementary transfer eligibility in Lower Saxony } & $-0,131$ & $-0,350$ * & $-0,478$ ** & $-0,572$ & $-1,261$ ** & $-1,606$ ** & $-1,785$ ** \\
\hline & 0,178 & 0,197 & 0,213 & 0,467 & 0,532 & 0,694 & 0,727 \\
\hline \multirow[t]{2}{*}{ Lower Saxony dummy } & $0,372 * \star *$ & 0,516 *** & $0,660 * \star *$ & $0,720 * \star \star *$ & $0,988 * \star \star *$ & $1,187 * \star \star$ & $1,273^{\star \star \star *}$ \\
\hline & 0,044 & 0,050 & 0,054 & 0,063 & 0,077 & 0,087 & 0,089 \\
\hline \multicolumn{8}{|l|}{ Probit specification $\mathrm{B}^{\mathrm{b})}$} \\
\hline \multirow[t]{2}{*}{ Supplementary transfer eligibility in Lower Saxony } & $-0,242$ & $-0,571$ & $-0,745$ * & $-0,577$ & $-1,270$ ** & $-1,419 * \star$ & $-1,586$ ** \\
\hline & 0,325 & 0,360 & 0,387 & 0,462 & 0,530 & 0,610 & 0,644 \\
\hline \multirow[t]{2}{*}{ Lower Saxony dummy } & $0,377 * \star \star$ & $0,516 * \star *$ & 0,658 *** & 0,716 *** & $0,974 * \star \star$ & $1,152 * \star \star *$ & $1,235 * \star \star$ \\
\hline & 0,043 & 0,048 & 0,052 & 0,059 & 0,073 & 0,082 & 0,085 \\
\hline \multicolumn{8}{|l|}{ Probit specification $\mathrm{C}^{\mathrm{c})}$} \\
\hline \multirow[t]{2}{*}{ Supplementary transfer eligibility in Lower Saxony } & $-0,220$ & $-0,552$ & $-0,744$ * & $-0,380$ & $-0,766$ *** & $-0,890 * * \star$ & $-0,974$ *** \\
\hline & 0,320 & 0,358 & 0,391 & 0,255 & 0,292 & 0,344 & 0,361 \\
\hline \multirow[t]{2}{*}{ Lower Saxony dummy } & 0,372 *** & $0,519 * * *$ & 0,670 *** & 0,714 *** & 0,978 *** & 1,165 *** & 1,246 *** \\
\hline & 0,046 & 0,052 & 0,057 & 0,061 & 0,075 & 0,084 & 0,087 \\
\hline
\end{tabular}

Notes: Supplementary transfer eligibility in Lower Saxony is endogenous. Reported estimates are average treatment effects of the treated for changes in business tax rates as compared to $1994-1997$ average levels.

a) Full second-order polynomial function: probit specification as in Table 2 plus interaction terms among the non-squared regressors.

b) Probit specification that only includes the following variables measuring area in hectares: agricultural land, forest land, watersheds, and their squared values.

c) Probit specification that only includes per-capita income as of 1993, population as of 1993, population density as of 1993, and the population share with age $\leq 15$ as of 1993. 


\section{CESifo Working Paper Series}

(for full list see www.cesifo-group.de)

1892 Erkki Koskela and Rune Stenbacka, Equilibrium Unemployment with Outsourcing under Labour Market Imperfections, January 2007

1893 Maarten Bosker, Steven Brakman, Harry Garretsen, Herman de Jong and Marc Schramm, The Development of Cities in Italy 1300 - 1861, January 2007

1894 Michel Beine, Oscar Bernal, Jean-Yves Gnabo and Christelle Lecourt, Intervention Policy of the BoJ: A Unified Approach, January 2007

1895 Robert S. Chirinko and Daniel J. Wilson, State Investment Tax Incentives: A Zero-Sum Game?, January 2007

1896 Theo S. Eicher and Oliver Roehn, Sources of the German Productivity Demise Tracing the Effects of Industry-Level ICT Investment, January 2007

1897 Helge Berger, Volker Nitsch and Tonny Lybek, Central Bank Boards around the World: Why does Membership Size Differ?, January 2007

1898 Gabriel Felbermayr and Wilhelm Kohler, Does WTO Membership Make a Difference at the Extensive Margin of World Trade?, January 2007

1899 Benno Torgler and Friedrich Schneider, The Impact of Tax Morale and Institutional Quality on the Shadow Economy, January 2007

1900 Tomer Blumkin and Efraim Sadka, On the Desirability of Taxing Charitable Contributions, January 2007

1901 Frederick van der Ploeg and Reinhilde Veugelers, Higher Education Reform and the Renewed Lisbon Strategy: Role of Member States and the European Commission, January 2007

1902 John Lewis, Hitting and Hoping? Meeting the Exchange Rate and Inflation Criteria during a Period of Nominal Convergence, January 2007

1903 Torben M. Andersen, The Scandinavian Model - Prospects and Challenges, January 2007

1904 Stephane Dees, Sean Holly, M. Hashem Pesaran and L. Vanessa Smith, Long Run Macroeconomic Relations in the Global Economy, January 2007

1905 Richard Jong-A-Pin and Jakob De Haan, Political Regime Change, Economic Reform and Growth Accelerations, January 2007

1906 Sascha O. Becker and Peter H. Egger, Endogenous Product versus Process Innovation and a Firm’s Propensity to Export, February 2007 
1907 Theo S. Eicher, Chris Papageorgiou and Oliver Roehn, Unraveling the Fortunates of the Fortunate: An Iterative Bayesian Model Averaging (IBMA) Approach, February 2007

1908 Liliana E. Pezzin, Robert A. Pollak and Barbara S. Schone, Efficiency in Family Bargaining: Living Arrangements and Caregiving Decisions of Adult Children and Disabled Elderly Parents, February 2007

1909 Christian Keuschnigg and Soren Bo Nielsen, Self-Selection and Advice in Venture Capital Finance, February 2007

1910 Rune Jansen Hagen and Gaute Torsvik, Irreversible Investments, Dynamic Inconsistency and Policy Convergence, February 2007

1911 Eric A. Hanushek and Ludger Woessmann, The Role of School Improvement in Economic Development, February 2007

1912 Bernard M. S. van Praag, Perspectives from the Happiness Literature and the Role of New Instruments for Policy Analysis, February 2007

1913 Volker Grossmann and Thomas M. Steger, Growth, Development, and Technological Change, February 2007

1914 Margarita Katsimi and Thomas Moutos, Human Capital and the Feldstein-Horioka Puzzle, February 2007

1915 Oliver Roehn, Theo S. Eicher and Thomas Strobel, The Ifo Industry Growth Accounting Database, February 2007

1916 Ian Babetskii, Aggregate Wage Flexibility in Selected New EU Member States, February 2007

1917 Burkhard Heer, Alfred Maussner and Paul D. McNelis, The Money-Age Distribution: Empirical Facts and Limited Monetary Models, February 2007

1918 Yin-Wong Cheung, Menzie D. Chinn and Eijii Fujii, The Overvaluation of Renminbi Undervaluation, February 2007

1919 Jim Malley, Apostolis Philippopoulos and Ulrich Woitek, To React or Not? Fiscal Policy, Volatility and Welfare in the EU-3, February 2007

1920 Mattias Polborn, Competing for Recognition through Public Good Provision, February 2007

1921 Lars P. Feld and Benno Torgler, Tax Morale after the Reunification of Germany: Results from a Quasi-Natural Experiment, February 2007

1922 Robert S. Chirinko and Huntley Schaller, Fundamentals, Misvaluation, and Investment: The Real Story, February 2007 
1923 Benno Torgler and Friedrich Schneider, Shadow Economy, Tax Morale, Governance and Institutional Quality: A Panel Analysis, February 2007

1924 Adrian Pagan and M. Hashem Pesaran, On Econometric Analysis of Structural Systems with Permanent and Transitory Shocks and Exogenous Variables, February 2007

1925 Hans-Werner Sinn, The Welfare State and the Forces of Globalization, February 2007

1926 Michael Smart, Raising Taxes through Equalization, February 2007

1927 Øystein Foros, Kåre P. Hagen and Hans Jarle Kind, Price-Dependent Profit Sharing as an Escape from the Bertrand Paradox, February 2007

1928 Balázs Égert, Kirsten Lommatzsch and Amina Lahrèche-Révil, Real Exchange Rates in Small Open OECD and Transition Economies: Comparing Apples with Oranges?, February 2007

1929 Aleksander Berentsen and Cyril Monnet, Monetary Policy in a Channel System, February 2007

1930 Wolfgang Ochel, The Free Movement of Inactive Citizens in the EU - A Challenge for the European Welfare State?, February 2007

1931 James K. Hammitt and Nicolas Treich, Statistical vs. Identified Lives in Benefit-Cost Analysis, February 2007

1932 Wilhelm Kohler, The Bazaar Effect, Unbundling of Comparative Advantage, and Migration, February 2007

1933 Karsten Staehr, Fiscal Policies and Business Cycles in an Enlarged Euro Area, February 2007

1934 Michele Bernasconi and Paola Profeta, Redistribution or Education? The Political Economy of the Social Race, March 2007

1935 Axel Dreher, Martin Gassebner and Lars-H. R. Siemers, Does Terror Threaten Human Rights? Evidence from Panel Data, March 2007

1936 Naércio Aquino Menezes Filho and Marc-Andreas Muendler, Labor Reallocation in Response to Trade Reform, March 2007

1937 Gebhard Flaig and Timo Wollmershaeuser, Does the Euro-zone Diverge? A Stress Indicator for Analyzing Trends and Cycles in Real GDP and Inflation, March 2007

1938 Michael Funke and Michael Paetz, Environmental Policy Under Model Uncertainty: A Robust Optimal Control Approach, March 2007

1939 Byeongchan Seong, Sung K. Ahn and Peter A. Zadrozny, Cointegration Analysis with Mixed-Frequency Data, March 2007 
1940 Monika Bütler and Michel André Maréchal, Framing Effects in Political Decision Making: Evidence from a Natural Voting Experiment, March 2007

1941 Giacomo Corneo and Olivier Jeanne, A Theory of Tolerance, March 2007

1942 Qing Hong and Michael Smart, In Praise of Tax Havens: International Tax Planning and Foreign Direct Investment, March 2007

1943 Yin-Wong Cheung, Dickson Tam and Matthew S. Yiu, Does the Chinese Interest Rate Follow the US Interest Rate?, March 2007

1944 Panu Poutvaara and Mikael Priks, Unemployment and Gang Crime: Could Prosperity Backfire?, March 2007

1945 Burkhard Heer, On the Modeling of the Income Distribution Business Cycle Dynamics, March 2007

1946 Christoph A. Schaltegger and Lars P. Feld, Are Fiscal Adjustments less Successful in Decentralized Governments?, March 2007

1947 Giovanni Facchini, Marcelo Olarreaga, Peri Silva and Gerald Willmann, Substitutability and Protectionism: Latin America's Trade Policy and Imports from China and India, March 2007

1948 C. Mirjam van Praag and Bernard M. S. van Praag, The Benefits of Being Economics Professor A (and not Z), March 2007

1949 Astrid Hopfensitz and Frans van Winden, Dynamic Choice, Independence and Emotions, March 2007

1950 Guglielmo Maria Caporale and Luis A. Gil-Alana, A Multivariate Long-Memory Model with Structural Breaks, March 2007

1951 Mattias Ganslandt and Keith E. Maskus, Wholesale Price Discrimination and Parallel Imports, March 2007

1952 Michela Redoano, Fiscal Interactions Among European Countries. Does the EU Matter?, March 2007

1953 Stefan C. Wolter, Rémy Hübschi and Matthias Müller, Push or Pull? An Empirical Analysis of the Demand for Individual Project Grants from the Swiss National Science Foundation, March 2007

1954 Scott Alan Carson, African-American and White Inequality in the American South: Evidence from the $19^{\text {th }}$ Century Missouri State Prison, March 2007

1955 Peter Egger, Marko Koethenbuerger and Michael Smart, Do Fiscal Transfers Alleviate Business Tax Competition? Evidence from Germany, March 2007 